ARTICLE

\title{
$B A D$ regulates mammary gland morphogenesis by 4E-BP1-mediated control of localized translation in mouse and human models
}

John Maringa Githaka1, Namita Tripathi, Raven Kirschenman', Namrata Patel1, Vrajesh Pandya1, David A. Kramer (10) ${ }^{1}$, Rachel Montpetit ${ }^{1}$, Lin Fu Zhu (1) ${ }^{2}$, Nahum Sonenberg (1) ${ }^{3}$, Richard P. Fahlman (1) ${ }^{1}$, Nika N. Danial (1) ${ }^{4}$, D. Alan Underhill ${ }^{5}$ \& Ing Swie Goping (1) $1,5 \bowtie$

Elucidation of non-canonical protein functions can identify novel tissue homeostasis pathways. Herein, we describe a role for the Bcl-2 family member BAD in postnatal mammary gland morphogenesis. In Bad ${ }^{3 S A}$ knock-in mice, where BAD cannot undergo phosphorylation at 3 key serine residues, pubertal gland development is delayed due to aberrant tubulogenesis of the ductal epithelium. Proteomic and RPPA analyses identify that BAD regulates focal adhesions and the mRNA translation repressor, 4E-BP1. These results suggest that BAD modulates localized translation that drives focal adhesion maturation and cell motility. Consistent with this, cells within Bad $35 A$ organoids contain unstable protrusions with decreased compartmentalized mRNA translation and focal adhesions, and exhibit reduced cell migration and tubulogenesis. Critically, protrusion stability is rescued by $4 \mathrm{E}-\mathrm{BP} 1$ depletion. Together our results confirm an unexpected role of BAD in controlling localized translation and cell migration during mammary gland development.

\footnotetext{
${ }^{1}$ Department of Biochemistry, University of Alberta, Edmonton, AB, Canada. ${ }^{2}$ Department of Surgery, University of Alberta, Edmonton, AB, Canada.

${ }^{3}$ Department of Biochemistry, McGill University, Montreal, QC, Canada. ${ }^{4}$ Department of Cancer Biology, Dana-Farber Cancer Institute, Boston, MA, USA.

${ }^{5}$ Department of Oncology, University of Alberta, Edmonton, AB, Canada. ${ }^{凶}$ email: igoping@ualberta.ca
} 
T he BH3-only Bcl-2-associated agonist of death protein $\mathrm{BAD}^{1}$ is best known as an apoptosis sensitizer, but has complex roles in vivo ${ }^{2-4}$. It is regulated by coordinated phosphorylation of three serine (S) residues S112, 136, and 155 $(75,99$, and 118 in humans) that differentially modulate activity in a tissue-specific manner ${ }^{5,6}$. Genetic knock-out and phosphomutant mice have apoptotic defects in the developing lymphoid compartment ${ }^{7,8}$, diminished glycolysis in the pancreas and liver 9,10 , and altered electrical activity in the brain ${ }^{11}$. In the breast, $\mathrm{BAD}$ is a prognostic marker for survival of breast cancer patients $^{12}$, and modulates mitochondrial metabolism and sensitivity to taxane chemotherapy in vitro ${ }^{13,14}$. Intriguingly, $\mathrm{BAD}$ is differentially expressed during mammary gland development in the mouse ${ }^{15}$, and deciphering this may shed light on pathophysiology as aberrant reactivation of these developmental pathways defines breast carcinogenesis ${ }^{16-18}$.

The female mammary gland undergoes extensive postnatal development including ductal morphogenesis in puberty, differentiation into a milk-producing organ in pregnancy/lactation and regression to a pre-pregnant state at weaning ${ }^{19}$. During puberty, estrogen and growth hormone trigger the formation of bulbshaped terminal end buds (TEBs) on the branch tips of the rudimentary epithelial anlage ${ }^{20}$. These TEBs consist of a multilayered mass of semi-differentiated myoepithelial and epithelial luminal cells that invade the mammary fat pad and repeatedly bifurcate to ultimately form an arborized ductal network. Individualistic cell migration within the TEBs mediates this forward growth involving partial epithelial to mesenchymal transition (EMT) with collective leader-follower characteristics ${ }^{21}$. Molecular mechanisms of cell motility have been exquisitely defined through $2 \mathrm{D}$ in vitro studies, identifying cycles of subcellular protrusion, adhesion, and contraction facilitated by the actomyosin cytoskeleton. Cell migration in 3D is more complex involving coordinated movement of groups of cells within complex microenvironments and thus knowledge gaps still exist on the molecular aspects of 3D and in vivo cell motility ${ }^{22}$.

Since BAD is associated with breast pathophysiology through an unknown biological mechanism, here we examine the effects of $\mathrm{BAD}$ and $\mathrm{BAD}$ phosphorylation-mutants on postnatal mammary gland development. Using a genetic mouse model wherein the three $\mathrm{S}$ residues are replaced by alanine $\left(B a d^{3 \mathrm{SA}}\right)^{7}$, we observe a pubertal stage-specific delay in the elongation of the epithelial ductal tree. Unbiased proteomic screens identify that $B a d^{3 \mathrm{SA}}$ dysregulates the mRNA translational repressor protein $4 \mathrm{E}-\mathrm{BP} 1$, focal adhesion and actin binding components, which together suggest defects to the cell motility machinery. It is known that localized mRNA translation stabilizes subcellular protrusions that are required for cell migration in vitro ${ }^{23-25}$. Consistent with this, $\mathrm{Bad}^{3 \mathrm{SA}}$ organoids have protrusions that are lacking in hyperphosphorylated 4E-BP1, are deficient for protrusion-localized translation, have destabilized protrusions and show inhibited cell migration and tubule outgrowth. Depletion of $4 \mathrm{E}-\mathrm{BP} 1$ rescues the $\mathrm{BAD}^{3 \mathrm{SA}}$-mediated protrusion defect. Thus, this work identifies $\mathrm{BAD}$ as a modulator of mammary gland morphogenesis and shows a regulatory link to localized translation that is critical for pubertal stage-specific cell migration.

\section{Results}

BAD phosphorylation regulates mammary gland morphogenesis in puberty. We used 3 genetic engineered mouse models to explore the role of BAD in postnatal mammary gland development; knock-out $\mathrm{Bad}^{-/-}$, knock-in $\mathrm{Bad}^{S 155 \mathrm{~A}}$ and $\mathrm{Bad}^{3 S A}$ where 3SA indicates alanine substitutions at $S 112 / 136 / 155$ of the endogenous Bad allele (gene in italics and protein in all uppercase) $)^{7,8,10}$. We first characterized $\mathrm{BAD}$ protein and phosphoprotein levels during mammary gland development in the wild-type animal. Serines 112,136 , and 155 are coordinately phosphorylated $^{26}$ and we used either anti-PS112 or anti-PS136 antibodies that were validated for western blot or immunofluorescence, to monitor phosphorylated BAD (P-BAD). Total BAD protein levels are similar in pubertal, nulliparous adult and involuting glands and elevated in pregnant glands (Fig. 1a). On the other hand, P-BAD is significantly elevated by $\sim 26$-fold, $\sim 18$ fold and $~ 11$-fold in puberty, pregnant and involuting gland respectively, relative to nulliparous adult. At the cellular level, total BAD localizes to the epithelial cells lining mature ducts and TEBs of the pubertal mammary gland and is largely undetected in the surrounding stroma (Fig. 1b). Notably, P-BAD, is locally enriched in the TEBs (Fig. 1c). These results suggest that P-BAD modulates pubertal-specific processes, likely related to its TEBlocalization.

We next surveyed whether phosphomutants of BAD have altered pubertal ductal morphogenesis. The mammary glands of $\mathrm{Bad}^{+/+}$animals undergo substantial growth and elongation during puberty (compare pubertal onset at $4 \mathrm{wk}$ vs puberty at 5wk; Fig. 2a-c and Supplementary Fig. 1). Bad ${ }^{S 155 A}$ and Bad $35 A$ glands, however, are significantly delayed with decreased ductal extension, ductal area, primary branching, and inconsistent branching (Fig. 2a-c and Supplementary Fig. 1). Mutation of S155 alone is sufficient to delay ductal elongation, although mutation of all three serines produces the strongest phenotype. In all other stages of pre-pubertal, adult, pregnant and involuting, Bad $^{3 S A}$ glands are morphologically normal (Supplementary Fig. 2). These results highlight that $\mathrm{Bad}^{3 S A}$ delays pubertal mammary gland development, which fully recovers by early adulthood. $\mathrm{Bad}^{-/-}$animals are not phenotypically different at any stage, indicating a dominant effect of non-P-BAD (Fig. 2a-c and Supplementary Fig. 2). Thus, pubertal specific signals induce phosphorylation of BAD and blocking this in $B a d^{3 S A}$ and Bad ${ }^{\text {155A }}$ animals, disturbs ductal morphogenesis.

$B^{3} d^{3 S A}$-mediated defect is epithelial cell autonomous. Ductal morphogenesis is coordinated through complex signals between the epithelial and stromal compartments ${ }^{27-30}$. Since the mice are whole-body genetic models, we transplanted epithelium from one genotype into the cleared fat pads of the opposite genotype to identify the origin of the defect (Fig. $2 \mathrm{~d}-\mathrm{f}$ ). Bad ${ }^{+/+}$epithelium transplanted into either $\mathrm{Bad}^{+/+}$or $\mathrm{Bad}^{3 S A}$ animals repopulates the recipient fat pads with equal efficiency and similar ductal expansion (Fig. 2f-h), indicating that the Bad $3{ }^{3 S A}$ stroma is competent for growth. In contrast, $\mathrm{Bad}^{3 S A}$ epithelium fails to grow in $\mathrm{Bad}^{+/+}$recipients (Fig. 2f, g), demonstrating that the defect resides within the $B a d^{3 S A}$ epithelium (Fig. 2g; $\chi^{2} p=$ 0.0235).

We directly examined epithelial effects with ex vivo 3D organotypic branching assays using primary mouse epithelial cell organoids isolated from the mouse mammary gland ${ }^{21,31-34}$. These primary mouse organoids were embedded in extracellular matrix (ECM) mimics of Matrigel:Collagen-I, where they form multicellular cysts similar to TEBs and recapitulate ductal morphogenesis (Fig. 3a) ${ }^{21,31}$. BAD is expressed and phosphorylated in these branching organoids, similar to whole glands (Supplementary Fig. 3a). Time-lapse microscopy shows that $\mathrm{Bad}^{3 S A}$ organoids produce similar proportion of organoids with branches but have significantly slower branch elongation and lower number of branches per organoid (Fig. 3b-d and Supplementary Fig. 3b, c). Thus, Bad ${ }^{3 S A}$ organoids phenocopy the ductal elongation delay and confirm the epithelial-specific defect.

To establish a genetically tractable system and also investigate conservation in human cells ${ }^{35}$, we utilized the MCF10A non- 
a

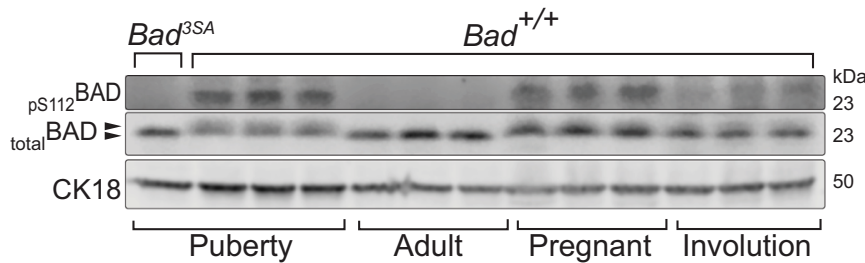

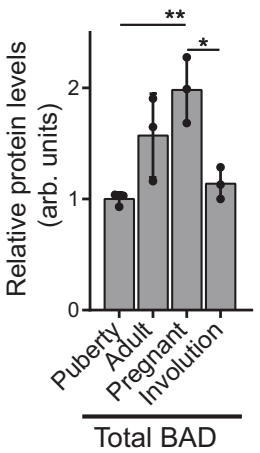

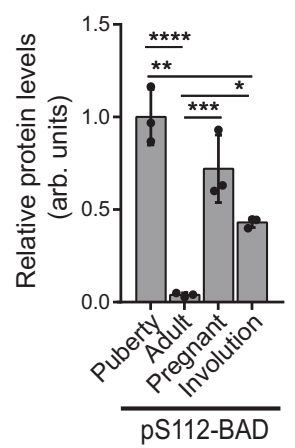

b

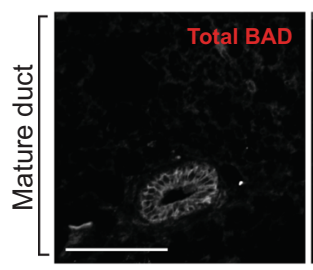

Mature
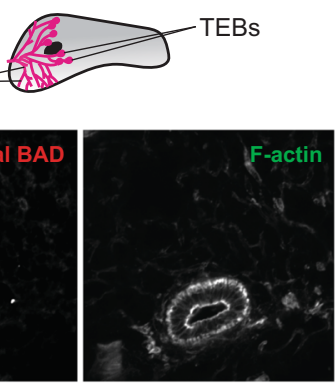

出

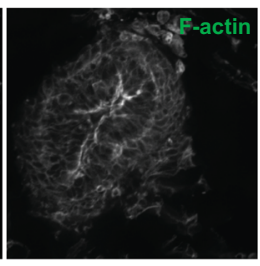

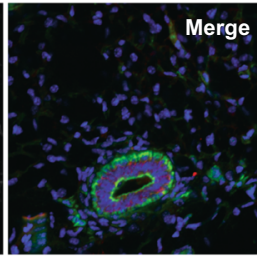

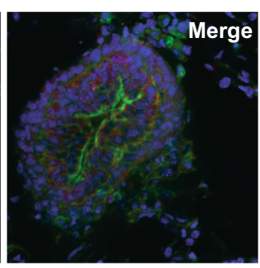

C
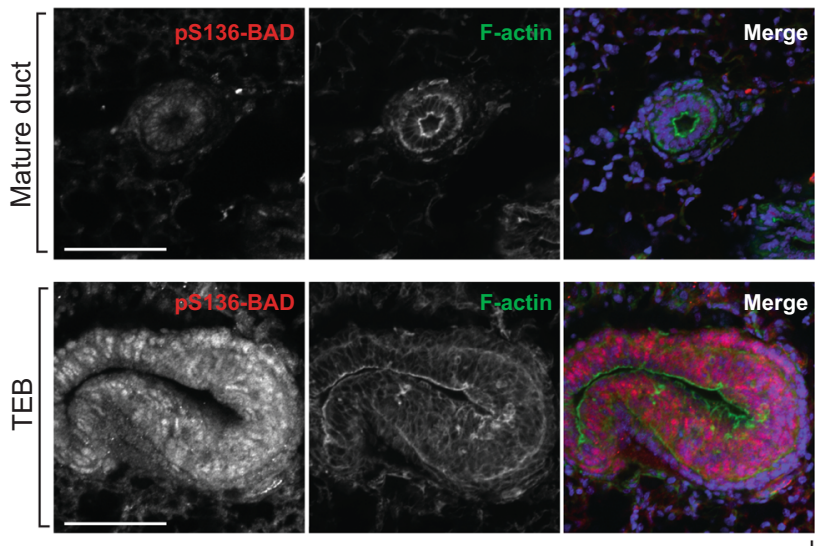

Pubertal mammary gland

Fig. 1 BAD is differentially phosphorylated in the developing mammary gland. a Left: western blots of P-BAD and total BAD from Bad $+/+$ mammary glands at indicated stages (Puberty at 5wk; Adult at 12wk; Pregnant; Involution). Each lane contains lysates from independent mice. Control Bad $35 A$ mammary gland lysate (first lane) shows specificity of anti-pS112-BAD antibody. Black arrowheads highlight gel shift indicative of BAD phosphorylation. CK18 is used as the loading control for the epithelial compartment. Middle: quantitation of total BAD relative to CK18 loading control, shows increased BAD levels in pregnancy with similar levels in other stages. Right: quantitation of pS112-BAD relative to total BAD shows decreased phosphorylation in adult glands with highest levels in pubertal stages. Data are mean \pm SD. For each stage, three independent mice were used. b, $\mathbf{c}$ Representative immunofluorescent images from $n=3$ independent mice of $\mathrm{Bad}^{+/+}$pubertal mammary glands stained for $\mathbf{b}$ total BAD and $\mathbf{c}$ P-BAD with pS136BAD antibody. The pubertal epithelial tree is composed of bilayer mature ducts capped by multilayer TEBs (inset schematic). Regions representing mature ducts (upper) and TEBs (lower) within the same tissue sections are shown. Total BAD (red), pS136-BAD (red), F-actin (green) and DAPI (blue). BAD localized to the epithelial cells in all experiments. bars $=100 \mu \mathrm{m}$. For all $p$-values, ${ }^{\star \star \star} P<0.001,{ }^{\star \star} P<0.01,{ }^{\star} P<0.05$. Statistical test details and exact $p$-values are provided in Supplementary Data 4. Source data are provided in the Source data file.

transformed breast cell line with a well-characterized model of 3D tubulogenesis ${ }^{36-39}$. When grown in 3D Matrigel:Collagen-I, MCF10A form multicellular cysts, where cells at the edge extend protrusions into the ECM and initiate collective cell migration to generate tubes, synonymous to mammary duct morphogenesis (Fig. 3e). We knocked-out expression of endogenous $B A D$ (human gene in all cap italics) ${ }^{13}$ and ectopically expressed human wild-type (WT) BAD or BAD3SA (herein, referred to as WT and 3SA, respectively). All experiments were conducted alongside an additional control of parental MCF10A cells, given the variable $\mathrm{BAD}$ expression levels (Fig. 3f). 3SA are significantly impaired in the overall formation of tubulating cysts with slower tubule extension (Fig. 3g-i), replicating the murine ductal elongation defect. Altogether, $\mathrm{BAD}^{3 \mathrm{SA}}$ inhibits mouse ductal elongation, with conserved effects in a $3 \mathrm{D}$ human cell tubulogenesis model.

$\mathrm{BAD}^{3 \mathrm{SA}}$ disrupts signatures related to cell motility. To investigate the mechanism, we conducted an unbiased mass spectrometry (MS) proteomic screen comparing $5 \mathrm{wk}-\mathrm{Bad}^{+/+}, 5 \mathrm{wk}-$ $\mathrm{Bad}^{3 S \mathrm{~A}}$ and $4 \mathrm{wk}-\mathrm{Bad}^{+/+}$mammary glands. We first validated whether the proteomic signature of $B a d^{3 S A}$ glands reflected a pubertal delay. Unsupervised hierarchical correlation clustering analysis indicates that the protein profile from the $5 \mathrm{wk}-\mathrm{Bad}^{3 S \mathrm{~A}}$ tissue clusters more closely with the $4 \mathrm{wk}$ rather than the agematched 5wk-Bad ${ }^{+/+}$mice (Supplementary Fig. 4a, see "Methods"). Further, the overall optimal number of clusters for the protein profiles is two groups ${ }^{40}$ (Supplementary Fig. 4b), and machine learning ensemble-based random forest analyses classifies $5 \mathrm{wk}-\mathrm{Bad} \mathrm{d}^{3 \mathrm{SA}}$ profiles as $4 \mathrm{wk}-\mathrm{Bad}^{+/+}$(Supplementary Fig. 4c, see "Methods"). Finally, Gene Ontology (GO) enrichment analysis produces strikingly similar molecular function and cellular function profiles between $5 \mathrm{wk}-\mathrm{Bad}^{+/+}$vs $4 \mathrm{wk}-\mathrm{Bad}^{+/+}$, and $5 \mathrm{wk}-$ $\mathrm{Bad}^{+/+}$vs 5wk-Bad ${ }^{3 S A}$ (Supplementary Fig. 4d and Supplementary Data 1). Thus, the proteomic profile of Bad ${ }^{3 S A}$ glands confirms the pubertal delay phenotype (see Fig. 2).

To identify cellular processes that are altered by $\mathrm{BAD}^{3 \mathrm{SA}}$, we analyzed the top GO hits. There are significant changes in the molecular function, "actin binding," and the cellular component, "focal adhesion", signifying that Bad $^{3 S A}$ disrupts cell migration processes (Supplementary Fig. 4d). Actin and focal adhesions are required for nascent protrusions to transition into stable protrusions that then connect to the ECM and facilitate cell 
a 4 wk (Pubertal onset)
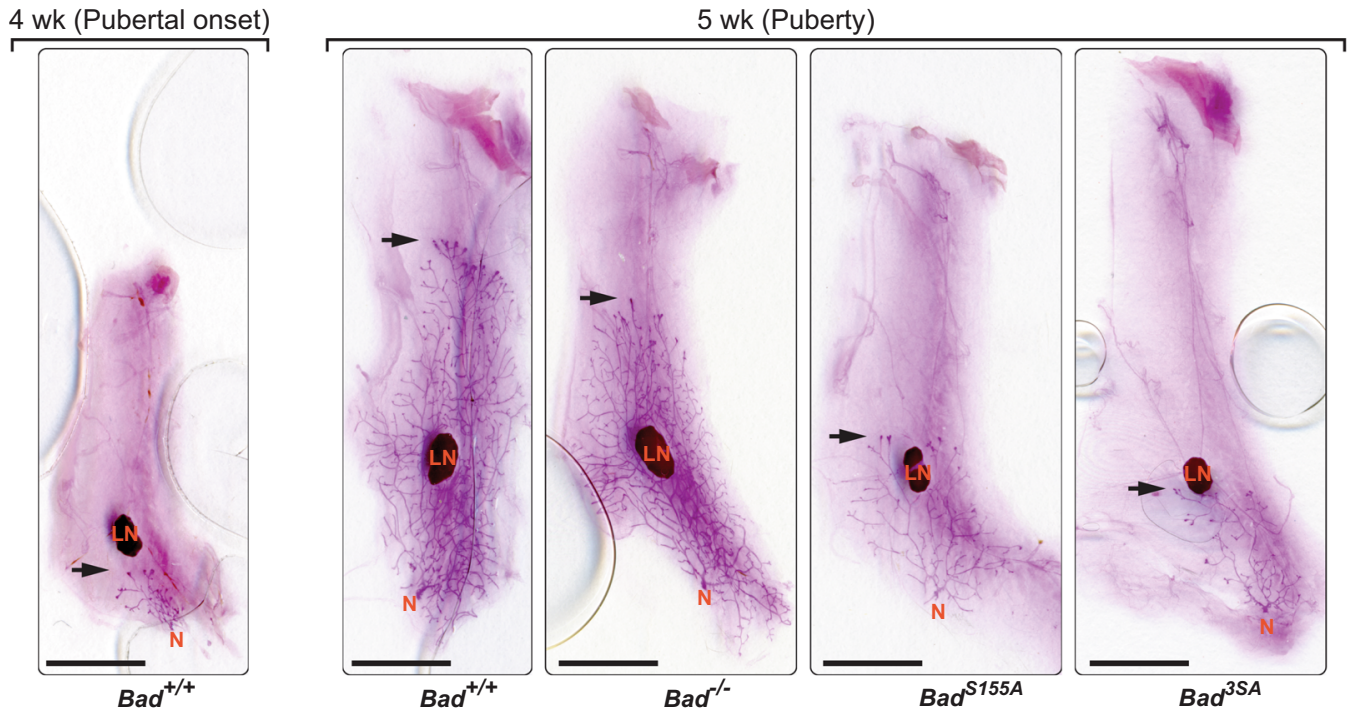

b

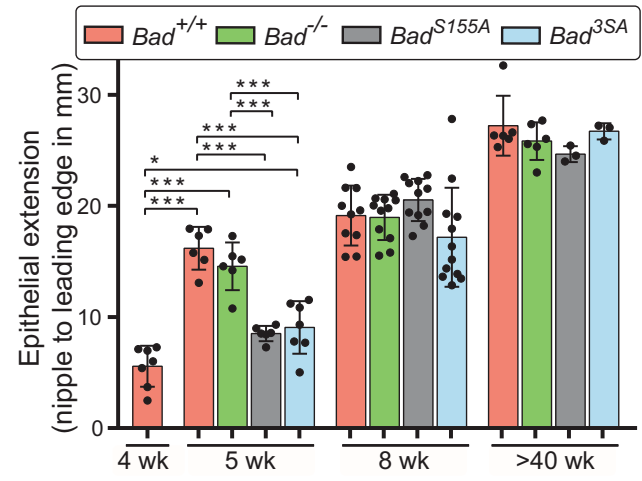

C

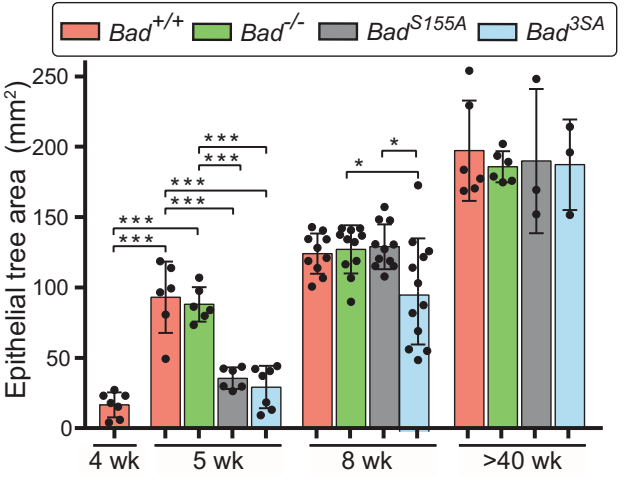

d
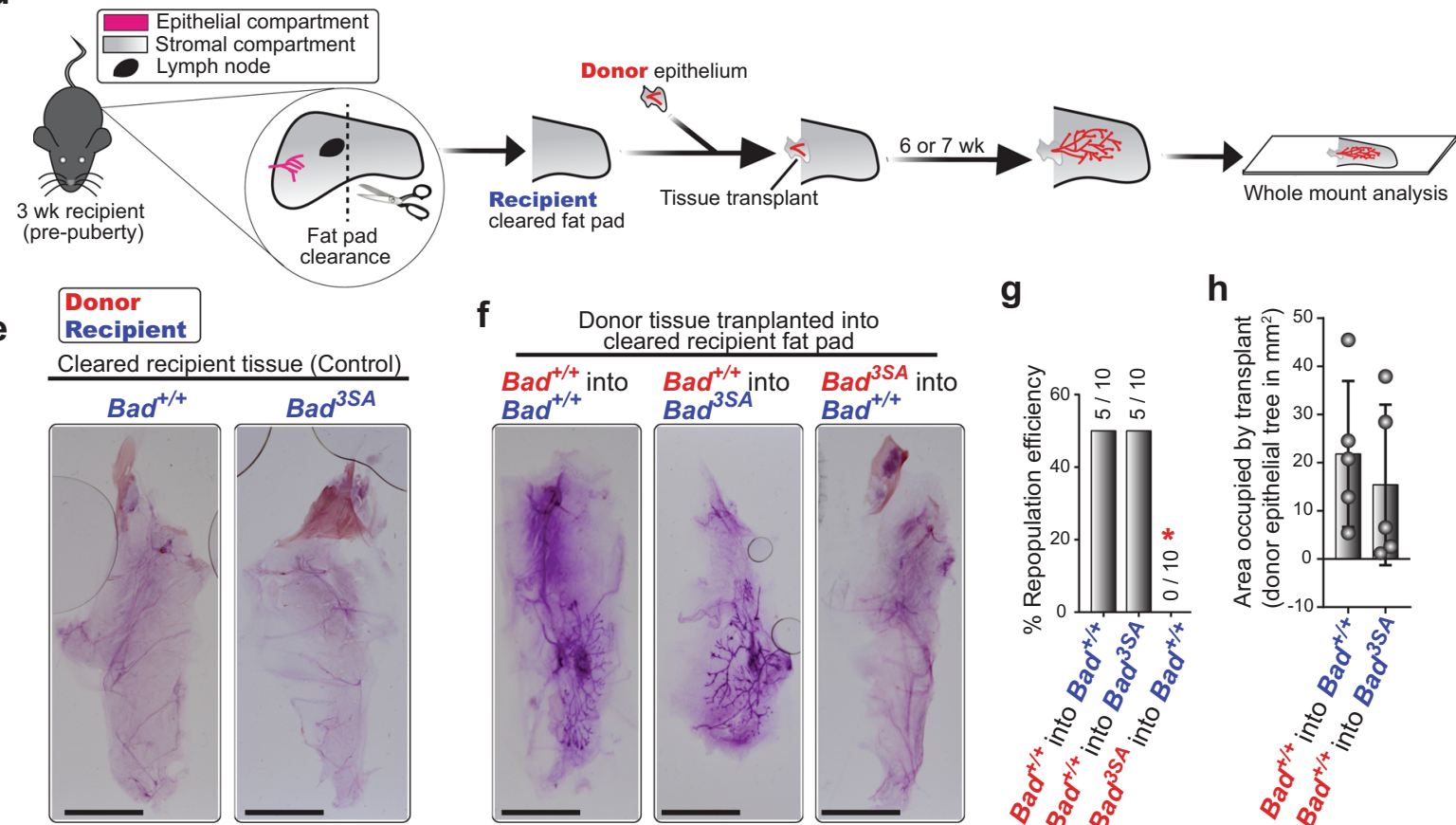

f

Donor tissue tranplanted into

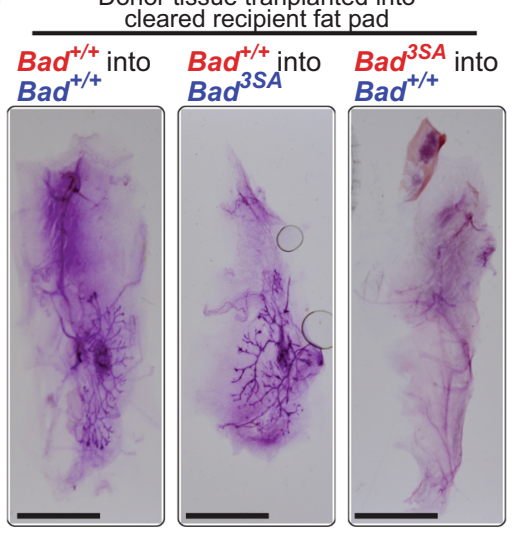

g

h
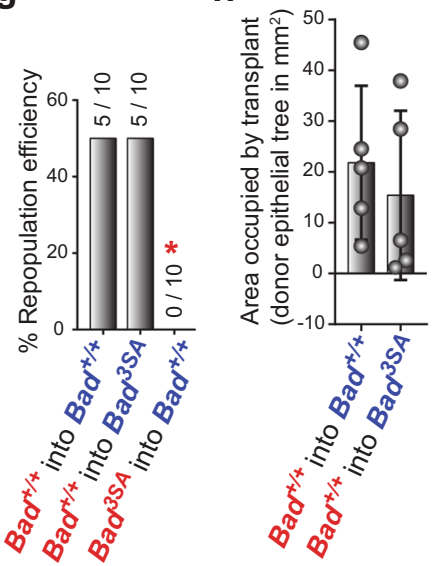

motility 41,42 . To test whether 3SA disrupts this process, we analyzed cell protrusion dynamics at day 3 of the $3 \mathrm{D}$ tubulogenesis assay (see Supplementary Movie 1). Figure 4 shows how cells at the edges of the multicellular cyst extend and contract protrusions into the ECM (Fig. 4a; green arrowheads). Upon focal adhesion maturation, these protrusions stabilize and facilitate collective cell migration to form tubules (Fig. 4a; red arrowheads). MCF10A WT and 3SA-expressing cysts are equally proficient at forming nascent protrusions (Fig. $4 \mathrm{~b}$ ), however, the 3SA protrusions are significantly less stable $(\sim 3 \times$ decreased lifetime) and shorter $(\sim 1.7 \times$ decreased length), revealing defects in adhesion stabilization (Fig. 4c). Nascent adhesions require 
Fig. 2 Bad $^{3 S A}$ shows defective mammary gland development in puberty that is derived from the epithelial compartment. a Representative carminestained mammary gland whole mounts (WMs) showing pubertal morphogenesis of Bad mutants. Shown are the \#4 mammary glands of 5 wk mice of $\mathrm{Bad}^{+/+}(n=6), \mathrm{Bad}^{-/-}(n=6), \mathrm{Bad}^{S 155 \mathrm{~A}}(n=6)$, and Bad $3 \mathrm{SA}(n=7)$. For comparison, a control Bad ${ }^{+/+}$gland at $4 \mathrm{wk}($ left, $n=7)$ representing early pubertal onset is included. The epithelial tree (dark pink branched structure) is embedded within the mammary fat pad (surrounding light pink stroma). $\mathrm{N}$, nipple; LN, lymph node. Arrows highlight front of migrating epithelial tree. Scale bars $=5 \mathrm{~mm}$. $\mathbf{b}$, c Quantitation of epithelial tree morphological features for $\mathrm{Bad}^{+/+}, \mathrm{Bad}^{-/-} \mathrm{Bad}^{5155 \mathrm{~A}}$, and Bad $3 \mathrm{SA}$ at different developmental times (5wk, 8wk, $>40 \mathrm{wk}$ ). b) Quantitation of epithelial tree extension shows delay in Bad $^{5155 A}$ (gray) and Bad $3 S A$ (blue) at 5wk. c Quantitation of epithelial tree area shows decreased area in Bad 5155 A (gray) at 5wk and Bad $35 A$ (blue) at 5wk and $8 w k$. Data are mean \pm SD. Number of animals: For pubertal onset $(4 \mathrm{wk}), \mathrm{Bad}^{+/+} n=7$. For puberty stage (5wk), towards end of puberty (8wk) and aged virgins (>40wk), Bad ${ }^{+/+} n=6,10,6 ; \mathrm{Bad}^{-/-} n=6,11,6 ; \mathrm{Bad}^{S 155 \mathrm{~A}} n=6,11,3$; and $\mathrm{Bad}^{3 S \mathrm{~A}} n=7,12,3$, respectively. d Transplant assay schematic showing fat pad clearance in recipient mouse and subsequent donor tissue transplant. Donor tissue growth was assessed 6 or 7 weeks post transplant surgery. e Representative carmine-stained WMs of negative control "recipient" mice ( $n=5$ mice per genotype) that did not receive transplant shows the efficiency of fat pad clearance. Scale bars $=5 \mathrm{~mm}$. $\mathbf{f}$ Representative carmine-stained WMs for experimental transplant series $(n=5 \mathrm{mice}$ per transplant condition). Red text represents the donor tissue genotype and blue text represents the recipient genotype. Scale bars $=5 \mathrm{~mm}$. $\mathbf{g}$ Percentage of cleared fat pads with successful transplant repopulation show failure of Bad ${ }^{3 S A}$ epithelium to repopulate fat pad (red asterisk). The ratio of successful repopulation per total transplants is shown on top of the bars. $n=10$ for each group. Computed Chi-square $\left(\chi^{2}\right) p$-value $=0.0235$. $\mathbf{h}$ Quantitation of area occupied by transplanted $\mathrm{Bad}^{+/+}$epithelium in either Bad ${ }^{+/+}$or Bad $3 \mathrm{SA}$ fat pads show similar repopulation areas. Data are mean \pm SD. $n=5$ for each group. For all $p$-values, ${ }^{\star \star \star} P<0.001,{ }^{\star \star} P<0.01,{ }^{\star} P<0.05$. Statistical test details and exact $p$-values are provided in Supplementary Data 4 . Source data are provided in the Source data file.

actin polymerization to mature into stable focal adhesions that provide traction for cell migration ${ }^{41}$. Indeed 3SA cell protrusions are deficient for both filamentous actin and the adhesion adapter protein paxillin (Fig. 4d, e). In contrast, WT protrusions show strong F-actin staining and punctate localization of paxillin, indicative of mature focal adhesions that mark protrusion stabilization (Fig. 4d, e). Intriguingly, 3SA does not decrease paxillin and F-actin staining in interior body cells within the multicellular cyst (Fig. 4e), indicating that 3SA specifically diminishes protein accumulation locally.

$\mathrm{BAD}^{3 \mathrm{SA}}$ defect does not depend on apoptosis. $\mathrm{BAD}^{3 \mathrm{SA}}$ has been shown to induce apoptosis ${ }^{7}$, so we examined whether apoptotic signaling mediates protrusion destabilization. As expected, cleaved caspase 3 is detected in the TEBs of the pubertal mammary gland ${ }^{20}$ but is not significantly increased in $\mathrm{Bad}^{3 S A}$ (Supplementary Fig. 5a). Additionally, blocking caspase activity with the pan caspase inhibitor $\mathrm{zVAD}$-fmk does not rescue protrusion defects in BAD ${ }^{3 S A}$ tubulogenesis assays (Supplementary Fig. 5b, c; Supplementary Movie 2). BAD stimulates apoptosis by binding to anti-apoptotic $\mathrm{Bcl}-\mathrm{XL}^{43}$. Although $\mathrm{BAD}^{3 \mathrm{SA}}$ binds strongly to $\mathrm{Bcl}-$ $\mathrm{XL}$ in the $3 \mathrm{D}$ culture system, disrupting this interaction with the BH3-mimetic ABT-737 (Supplementary Fig. 5d) does not alter the ability of $\mathrm{BAD}^{3 \mathrm{SA}}$ to inhibit protrusion stability (Supplementary Fig. 5b). Thus, the mechanism whereby BAD ${ }^{3 S A}$ inhibits ductal elongation does not require Bcl-XL interaction or caspase activity and is independent of apoptosis.

$\mathrm{BAD}^{3 \mathrm{SA}}$ defect does not alter epithelial cell lineage. We next tested if $\mathrm{BAD}^{3 \mathrm{SA}}$ alters epithelial cell lineage or the proportion of stem-like cells (Supplementary Fig. 6). To examine epithelial cell lineage, primary mouse mammary epithelial cells were stained for the surface markers CD24 versus CD $49 \mathrm{f}^{44}$. There is no significant difference in levels or proportion of luminal or basal epithelial subtypes. We next examined the epithelial stem/progenitor pools with the markers EpCAM versus CD49f to identify the Mammary Repopulating Unit (MRU) stem cells ${ }^{45}$. MRUs can generate an entire functional mammary gland from a single cell ${ }^{46}$. There is no difference in the MRU between the genotypes. Therefore, the $B a d^{3 S A}$ defect likely manifests downstream of epithelial lineage commitment.

BAD $^{3 S A}$ impedes 4E-BP1 hyperphosphorylation. To gain molecular insight into novel pathway(s) deregulated by Bad $35 A$, we performed a reverse phase protein array (RPPA) antibodybased screen. By quantitating protein/phosphoprotein levels of key regulators of cancer and developmental pathways ${ }^{47,48}$, RPPA can identify signal transduction differences with higher sensitivity than our MS-based screen ${ }^{49}$. BAD is phosphorylated in both $4 \mathrm{wk}$ and $5 \mathrm{wk} \mathrm{Bad} \mathrm{Ba}^{+/+}$glands but not in $\mathrm{Bad}^{3 S A}$, serving as an excellent internal control for RPPA specificity (Fig. 5a, b). Similar to the MS results, unsupervised hierarchical correlation clustering analysis and random forest classification shows a closer alignment between $5 \mathrm{wk}-\mathrm{Bad}^{3 S A}$ and $4 \mathrm{wk}-\mathrm{Bad}^{+/+}$glands rather than to the age-matched $\mathrm{Bad}^{+/+}$confirming $\mathrm{Bad}^{3 S A}$ imparts a developmental delay (Supplementary Fig. 7a, b). Analysis of variance and Tukey-Kramer multiple comparison post-hoc analysis was used to identify significant differences between all groups (Supplementary Data 2). Pathway analysis of significantly different hits (Supplementary Data 2) identifies "Focal Adhesion-PI3K-Akt-mTOR" as the most enriched expressed signaling pathway (Supplementary. Data 3, Supplementary Fig. 7c), confirming that $\mathrm{Bad}^{3 S A}$ disrupts focal adhesion processes. Of the 8 most significantly different protein/phosphoproteins between age-matched $\mathrm{Bad}^{+/+}$and $\mathrm{Bad}^{3 S A}$ ( $p$-value $<0.01$ ), the top 3 hits, mTOR, 4E-BP1, and eIF4E (Fig. 5a, b), are all markers of the top-ranked Focal Adhesion-PI3K-Akt-mTOR pathway. Since mTOR, 4E-BP1, and eIF4E are modulators of mRNA translation, these results implicate an unexpected role for $\mathrm{BAD}$ in this pathway.

The mTORC1 kinase complex stimulates the translation of capped mRNAs in part by phosphorylating and inhibiting the translational repressor, $4 \mathrm{E}-\mathrm{BP} 1^{50-52}$. In its hypophosphorylated state, 4E-BP1 binds the cap-binding protein eIF4E blocking subsequent recruitment of eIF4G, which is required to form the initiation complex eIF4F $\mathrm{F}^{52}$. mTORC1 sequentially phosphorylates $4 \mathrm{E}-\mathrm{BP} 1$ at T70 and S65 to generate the hyperphosphorylated state, causing the release of eIF4E to allow eIF4F complex assembly and translation initiation ${ }^{50-52}$. We verified RRPA hits on independently collected mammary gland tissue lysates and $3 \mathrm{D}$ cultures of murine organoids or human MCF10A cells. mTOR differences are not consistent in all systems analyzed (Fig. 5b-e). Dysregulation of the mTORC1 downstream target, 4E-BP1 however, is confirmed in all models (Fig. 5b-e). 4E-BP1 is significantly hyperphosphorylated in normal $5 \mathrm{wk}$ pubertal glands compared to both $4 \mathrm{wk}$ and $5 \mathrm{wk}-$ Bad $^{3 S A}$ (Fig. $5 \mathrm{~d}$ ). This suggests that cap-dependent translation naturally increases during pubertal development and this is blocked by $\mathrm{Bad}^{3 S A}$. Lysates from primary Bad $^{3 S A}$ expressing mouse organoids and MCF10A 

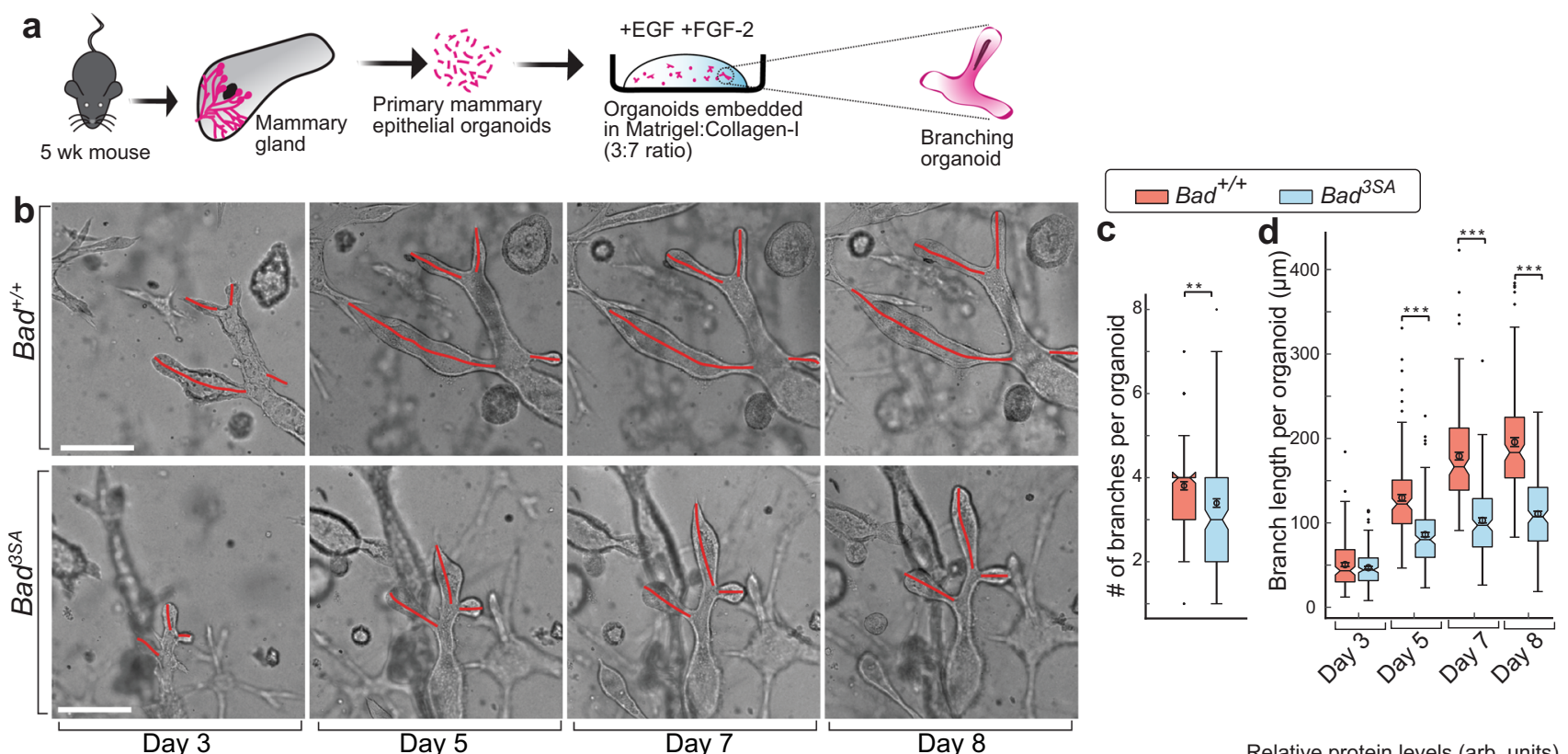

e
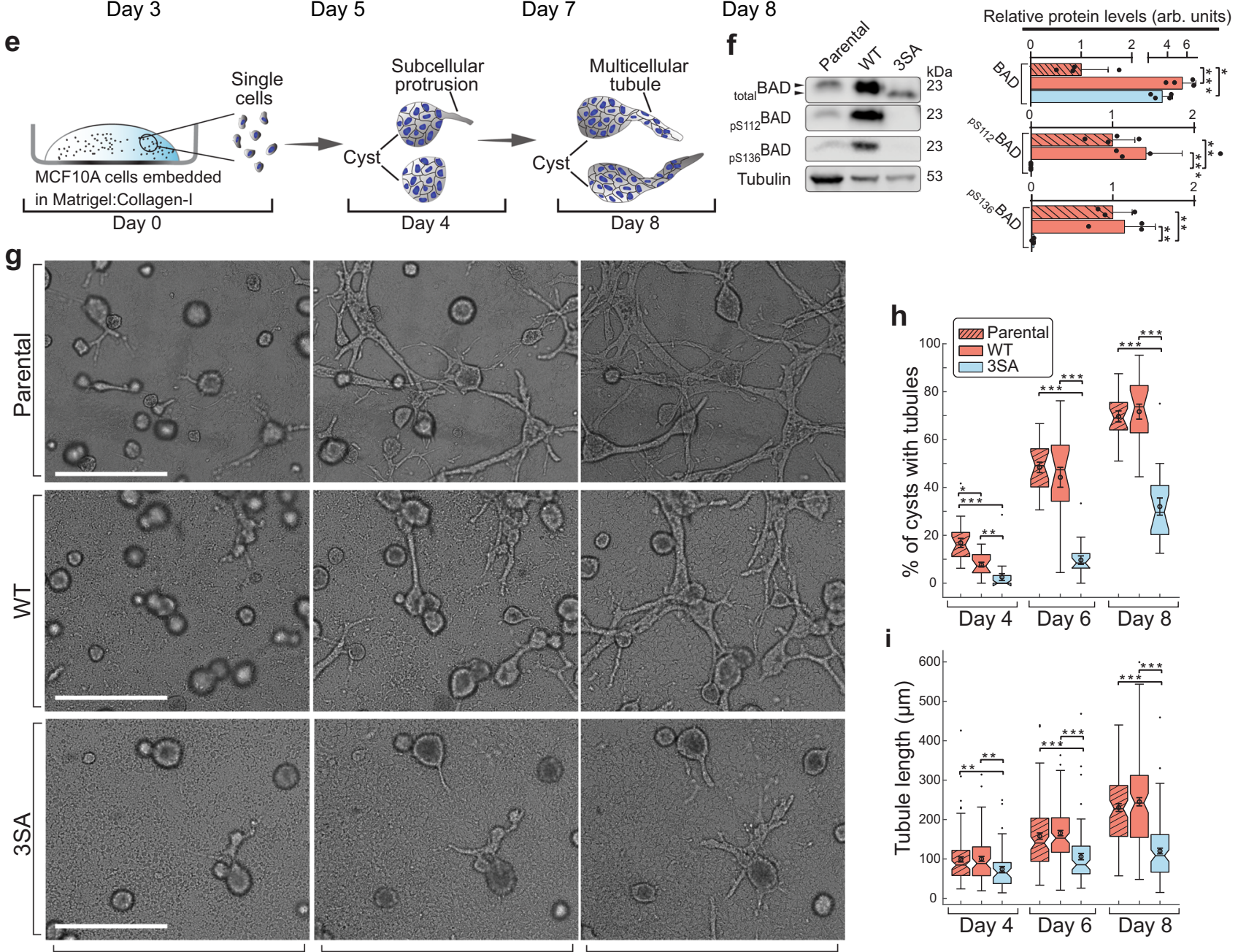

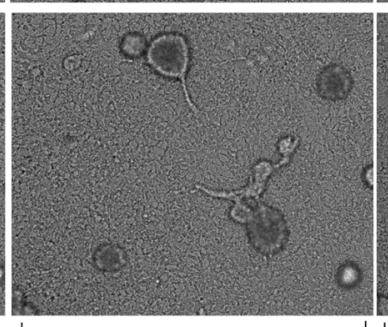

Day 6

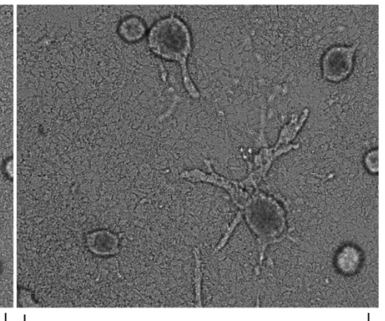

h
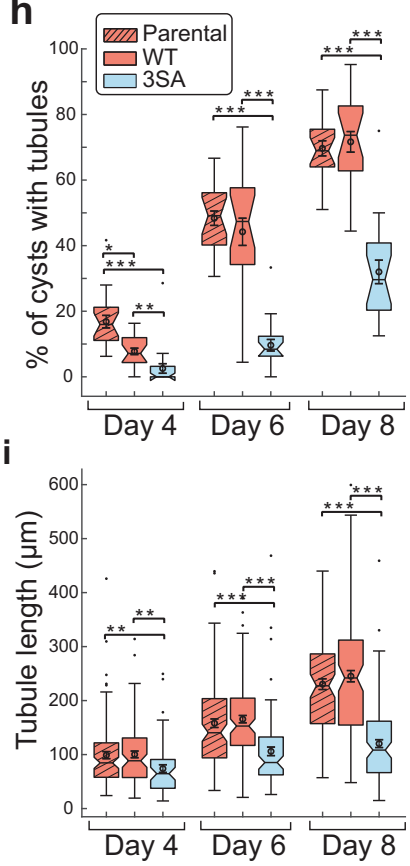

tubules also have decreased levels of hyperphosphorylated 4EBP1 (4E-BP1_p65) (Fig. 5e and Supplementary Fig. 7g). To confirm non-significant outcomes from the RPPA, there are no differences in total and active AKT and ERK1/2 kinases, which both contribute to mTORC1 activation and mammary gland morphogenesis ${ }^{53,54}$ (Supplementary Fig. 7d-g). Altogether, mammary epithelial cells expressing $\mathrm{BAD}^{3 \mathrm{SA}}$ have elevated hypophosphorylated 4E-BP1 species, predicting translational repression via inhibitory complex formation between hypophosphorylated 4E-BP1 and eIF4E. 
Fig. 3 3D tissue organoid branching and MCF10A tubulogenesis assays show non-phosphorylatable BAD imparts defects. a Schematic for 3D mouse organoid branching assay. EGF, epidermal growth factor; FGF-2, basic fibroblast growth factor. $\mathbf{b}$ Representative bright-field time-lapse images for Bad $+/+$ (upper) and Bad $35 A$ (lower) organoid branching assays from three independent experiments, 2 replicates per experiment. Bad $+/+n=150$ organoids, $B^{3 S A} n=185$ organoids. Red lines highlight individual branches used for quantitative measurements in (c, d). Scale bars $=200 \mu$ m. c Quantitation of number of branches per organoid. Data are represented as Tukey boxplots between Bad ${ }^{+/+}$(orange) and Bad $3 S A$ (blue) organoids. d Quantitation of mean branch length per organoid. Data are represented as Tukey boxplots and show decreased branch length in Bad $35 A$ (blue) organoids. Three independent experiments, 2 replicates per experiment. Bad ${ }^{+/+} n=150$ organoids, Bad $3 S A n=185$ organoids. e Schematic for 3D MCF10A tubulogenesis assay. $\mathbf{f}$ Left: western blots showing total BAD, pS112BAD, and pS136BAD in normal MCF10A (Parental) and WT and 3SA cells. Lysates were prepared from 3D tubulogenesis assays (day 7). Black arrowheads highlight gel shift indicative of BAD phosphorylation. Right: Quantitation of western blots. Data are mean \pm SD of four independent experiments. $g$ Representative bright-field time-lapse images for 3D MCF10A tubulogenesis assays of Parental (upper), WT (middle), and 3SA (lower) from three independent experiments. Fields of views for Parental $n=20$, WT $n=21,3 S A n=20$. Scale bars $=500 \mu$ m. h Percentage of cysts with branches (i.e., undergoing tubulogenesis). Tukey boxplots show decreased proportion of branching cysts in $3 S A$ (blue). Fields of views analyzed, Parental $n=20$, WT $n=21,3 S A n=20$. $\mathbf{i}$ Quantitation of mean tubule length. Tukey boxplots show decreased tubule length in 3SA (blue). Three independent experiments, 2 replicates per experiment. Number of tubules analyzed, Parental $n=90$, WT $n=103$, 3SA $n=104$. For Tukey boxplots, constriction indicates median, notch indicates $95 \%$ confidence interval, box edges are 25th and 75th percentiles, whiskers show extreme data points, 'outliers' plotted as black dots, overlaid circle, and error bars are the mean \pm SEM. For all $p$-values, ${ }^{\star \star \star} P<0.001,{ }^{\star \star} P<0.01,{ }^{\star} P<0.05$. Statistical test details and exact $p$-values are provided in Supplementary Data 4. Source data are provided in the Source data file.

$\mathrm{BAD}^{3 \mathrm{SA}}$ dysregulates $4 \mathrm{E}-\mathrm{BP1}$ interactions and localization. Hypophosphorylated 4E-BP1 inhibits translation by binding eIF4E and occluding the recruitment of eIF4G, which is normally required for subsequent eIF4F formation and translation initiation $^{50-52}$. To examine whether 3SA disrupts normal eIF4E protein interactions, we used a $\mathrm{m}^{7} \mathrm{GTP}$-cap pull-down assay to isolate cap-bound eIF4E. Indeed, there is increased 4E-BP1 associated with eIF4E, with corresponding decreased association of eIF4G to eIF4E in 3SA-expressing cells compared to parental MCF10A and WT (Fig. 6a). Since 3SA induces protrusionspecific defects, we next assessed whether 4E-BP1 or eIF4E are differentially localized to protrusions. The body cells within the multicellular cysts and subcellular protrusions show similar levels of total eIF4E and 4E-BP1 in both WT and 3SA (Fig. 6b; Supplementary Fig. 8a). Hyperphosphorylated 4E-BP1 (p65_4EBP1), however, is differentially expressed. It is similarly expressed in the body cells between the two genotypes, yet intriguingly, hyperphosphorylated $4 \mathrm{E}-\mathrm{BP} 1$ is significantly reduced in $3 \mathrm{SA}$ protrusions ( 2-fold decrease). Thus, 3SA protrusions are enriched for hypophosphorylated 4E-BP1 that is bound to eIF4E and prevents recruitment of eIF4G. Altogether these results suggest that 3SA inhibits mRNA translation locally within protrusions.

$\mathrm{BAD}^{3 \mathrm{SA}}$ inhibits localized mRNA translation with reduced protrusion stability and cell motility. Cell migration requires compartmentalized assembly of regulatory signaling molecules and cytoskeletal/adhesion proteins at the sites of cellular protrusions. Much of this spatial organization is driven by localized mRNA translation $23,25,55,56$. Given that we observed protrusionspecific depletion of F-actin and paxillin (Fig. 4d, e), we hypothesized that 3SA disrupted localized translation required for motility. To test whether 3SA indeed diminishes translation, we evaluated protein synthesis in $3 \mathrm{D}$ tubulogenesis assays. Using the surface sensing of translation (SUnSET) assay ${ }^{57}$, puromycin is incorporated into growing polypeptide chains generating truncated puromycinylated peptides ${ }^{58}$ that are visualized with antipuromycin antibodies ${ }^{23,57}$ (Supplementary Figs. 8b, c and 9). $\mathrm{Bad}^{+/+} 3 \mathrm{D}$ primary mouse organoid cultures have a significant $\sim 2$-fold increased puromycinylated peptide staining in areas of branch elongation relative to cells within the organoid body (Supplementary Fig. 8d). This localized protein synthesis is reduced in $\mathrm{Bad}^{3 S A}$ organoid branches. Parental and WT MCF10A tubules similarly have elevated translation in areas of tubule elongation that is significantly decreased in 3SA protrusions (Fig. 6c; Supplementary Fig. 8e). In support of a regional effect, global translation is unaffected by 3SA (Supplementary Fig. 8b, c).
Further, a bicistronic fluorescent reporter assay shows that 3SA reduced cap-dependent and -independent translation in protrusions (Supplementary Fig. 8f). Thus, mRNA translation is enriched in localized areas of ductal/tubule elongation in both primary mouse and human cell line $3 \mathrm{D}$ organoid analyses, and this is inhibited by $B a d^{3 S A}$.

4E-BP1 inhibits protrusion stabilization. If 3SA-dependent motility defects are indeed due to translational inhibition, then downregulation of $4 \mathrm{E}-\mathrm{BP} 1$ should rescue the defect. To test this, we generated stable 4E-BP1 knockdowns in the WT and 3SA MCF10A cell lines (Fig. 7a) and conducted 3D tubulogenesis time-lapse analyses. 3SA nascent subcellular protrusions have a significantly shorter lifetime than WT cells, and this is completely rescued with 4E-BP1 knockdown (Fig. 7b, c and Supplementary Movie 3), demonstrating that 3SA destabilizes protrusions via 4E$\mathrm{BP} 1$. Interestingly, 4E-BP1 knockdown increases protrusion stability in both 3SA and WT cells, such that nearly all cysts have stable protrusions by the end of the time course (Fig. 7f). Interestingly, these stable protrusions, are incompetent for elongation and do not form tubes (Fig. 7c-e, g and Supplementary Movie 3). This suggests that $4 \mathrm{E}-\mathrm{BP} 1$ destabilizes protrusions not only in 3SA-expressing cells, but also in normal control nascent protrusions. Therefore 4E-BP1 blocks the transition from nascent to stable protrusions. 3SA inhibits protrusion stabilization by facilitating 4E-BP1 hypophosphorylation, thus supporting the ability of $4 \mathrm{E}-\mathrm{BP} 1$ to block translation and protrusion elongation.

\section{Discussion}

Our data identify unexpected roles for BAD phosphorylation and localized mRNA translation in mammary gland development. We propose a working model whereby in puberty, ductal epithelial cells stimulate compartmentalized translation via localized phosphorylation/inactivation of the translational inhibitor $4 \mathrm{E}$ BP1. Non-P-BAD (BAD $\left.{ }^{3 S A}\right)$ blocks this hyperphosphorylation of $4 \mathrm{E}-\mathrm{BP} 1$ such that hypophosphorylated 4E-BP1 binds and represses eIF4E-mediated translation. This thereby represses localized translation required for focal adhesion maturation, cell protrusion stability, cell motility, and ultimately mammary gland morphogenesis (Fig. 8).

An intriguing observation is that while non-P-BAD knock-in mice $\left(B a d^{3 S A}\right)$ have delayed mammary gland pubertal development, the Bad knock-out animals are phenotypically normal. In fact, even though Bad expression is upregulated in the mammary gland during late pregnancy, lactation, and involution, our study 


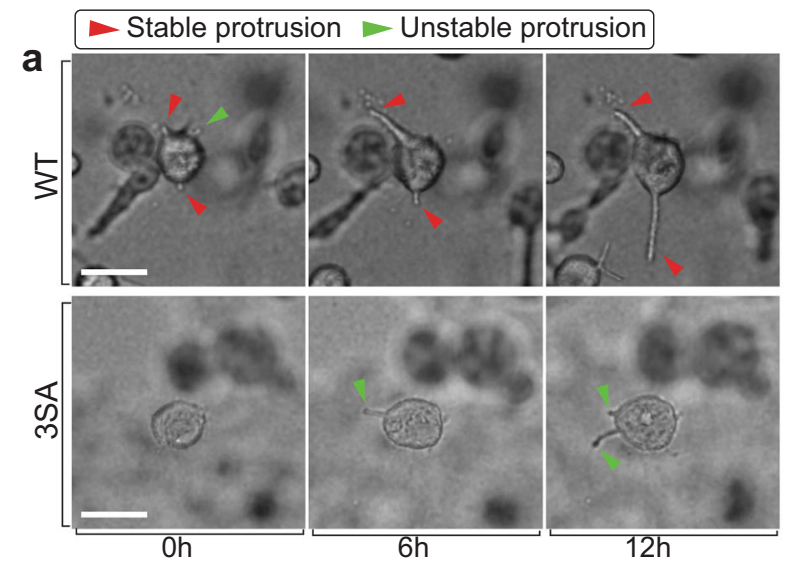

b

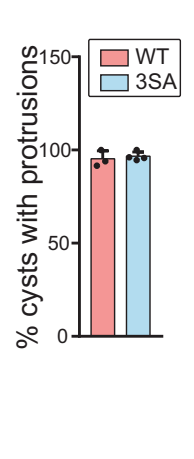

C

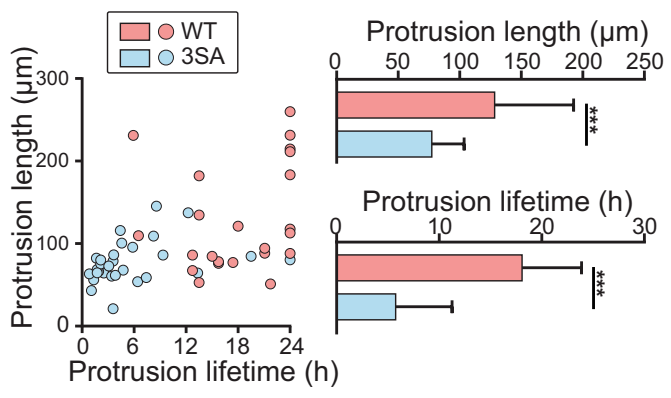

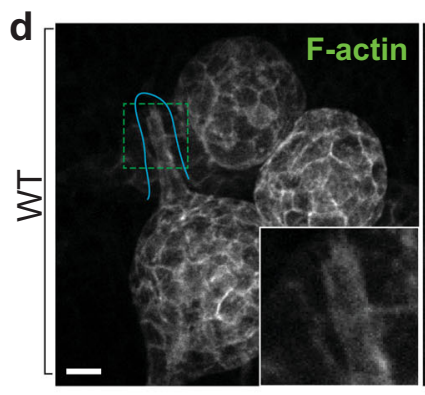

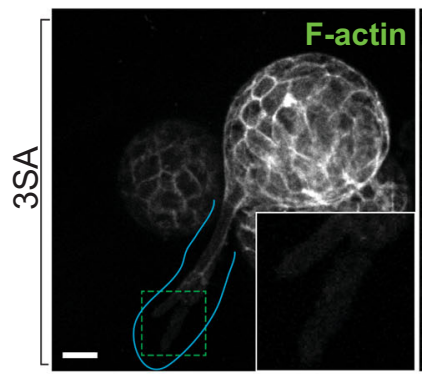

Protrusion outline
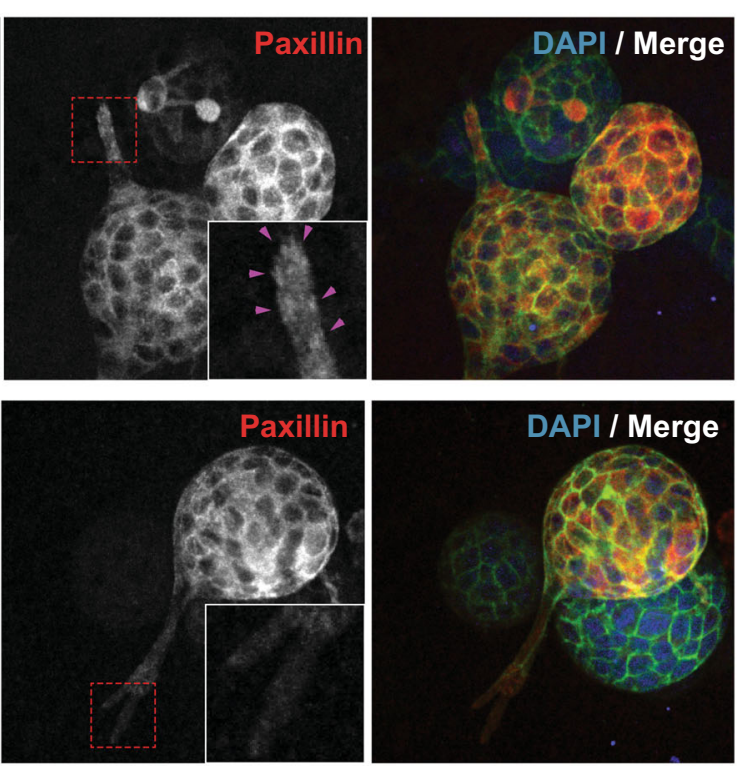

e

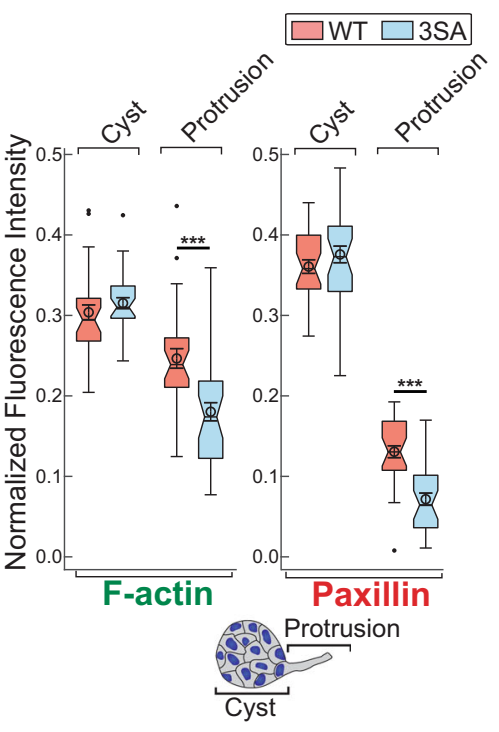

Fig. 4 3D MCF10A cysts from 3SA have unstable protrusions. a Representative bright-field time-lapse images of WT (upper) and 3SA (lower) MCF10 cysts in early 3D tubulogenesis assays, from three independent experiments. WT $n=23,3 S A n=29$ cysts (for complete time-lapse images, see Supplementary Movie 1). Individual subcellular protrusions either lengthen over time (red arrowheads) or are unstable and retract (green arrowheads). Scale bars $=100 \mu \mathrm{m}$. b Percentage of cell cysts that produced nascent protrusions (\% cysts with protrusions) was not different between WT and 3SA. 3 independent experiments. c The length and lifetime of individual protrusions are shown as a scatter plot comparing WT (orange dots) and 3SA (blue dots). Quantitation shows decreased protrusion length (upper) and decreased protrusion lifetime (lower) in 3SA (blue). WT $n=23,35 A n=29$, from three independent experiments. d Representative immunofluorescence images of cysts from WT (upper) and 3SA (lower) early tubulogenesis assays (day 4) stained with phalloidin (F-actin, green), anti-paxillin (focal adhesion marker, red) and DAPI (blue). DAPI highlights the nuclei in the multicellular cysts, and absence or presence of nuclei in the protrusions. The teal line is placed to outline subcellular protrusions subject to subsequent quantification analyses. Insets represent magnified areas indicated by dashed line boxes. Magenta arrowheads in the paxillin channel point to focal adhesion plaques. Scale bars $=$ $20 \mu \mathrm{m}$. WT $n=30,3 S A n=33$, from three independent experiments. e Tukey boxplots show quantitation for normalized F-actin (left) or paxillin (right) fluorescence intensity in either the cells within the cyst (Cyst) or subcellular protrusions (Protrusion). Below is a schematic of the multicellular cyst (Cyst) with a subcellular protrusion (Protrusion). WT and 3SA show similar F-actin and paxillin staining in the cells within the cyst (Cyst). 3SA (blue) shows decreased F-actin (left) and paxillin (right) staining in the protrusion (Protrusion). WT $n=30,3 \mathrm{SA} n=33$, from three independent experiments. For Tukey boxplots, constriction indicates median, notch indicates $95 \%$ confidence interval, box edges are 25th and 75th percentiles, whiskers show extreme data points, "outliers" plotted as black dots, overlaid circle, and error bars are the mean \pm SEM. For all $p$-values, ${ }^{\star \star \star} P<0.001,{ }^{\star \star} P<0.01,{ }^{\star} P<0.05$. Statistical test details and exact $p$-values are provided in Supplementary Data 4. Source data are provided in the Source data file.

and others show that the knock-out mammary gland is phenotypically normal ${ }^{15,59}$. Our study, therefore, indicates that P-BAD is relatively inert, whereas forced expression of non-P-BAD $\left(B a d^{3 S A}\right)$ has a dominant effect. This likely has in vivo relevance because $B a d^{3 S A}$ only affected pubertal development, a stage when wild-type $\mathrm{BAD}$ is normally phosphorylated. Wild-type P-BAD localizes to the TEBs, which are structures that appear in puberty and regress in adulthood ${ }^{60}$. As such BAD is not phosphorylated in the post pubertal mammary gland, when cell migration ceases.
Thus, BAD is normally phosphorylated in puberty and passively permits cell migration in the TEBs. Its non-phosphorylated counterpart in $\mathrm{Bad}^{3 S A}$ actively blocks migration.

$B a d^{3 S A}$ delays pubertal development but does not fully block ductal morphogenesis. This suggests that cells utilize compensatory mechanisms to achieve motility, as described in a 'multiparameter tuning model' 61 . Indeed, other genetic studies show similar transient pubertal delay and interestingly, those targeted genes fall within the signaling pathway affected by $\mathrm{Bad}^{3 S A}$. For 


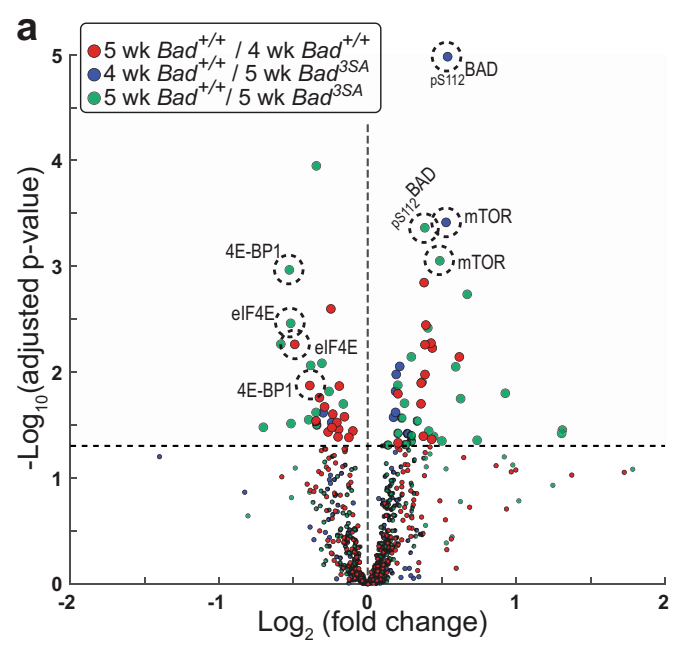

b

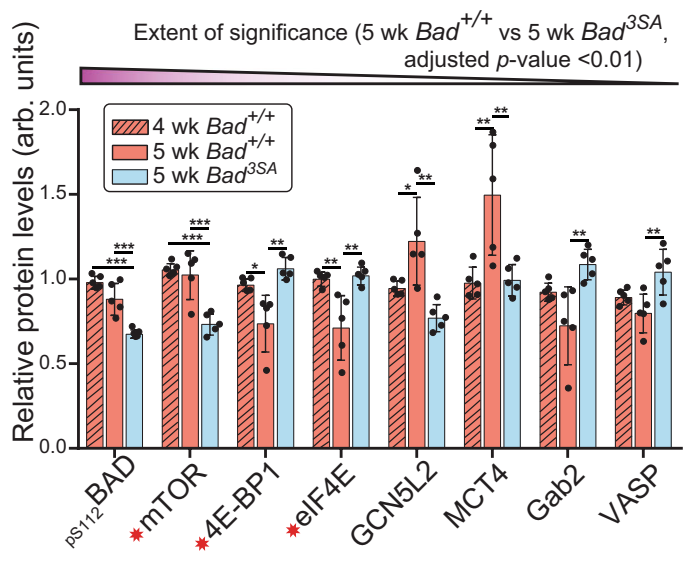

C

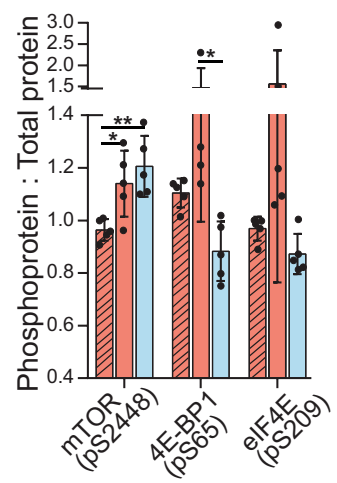

d
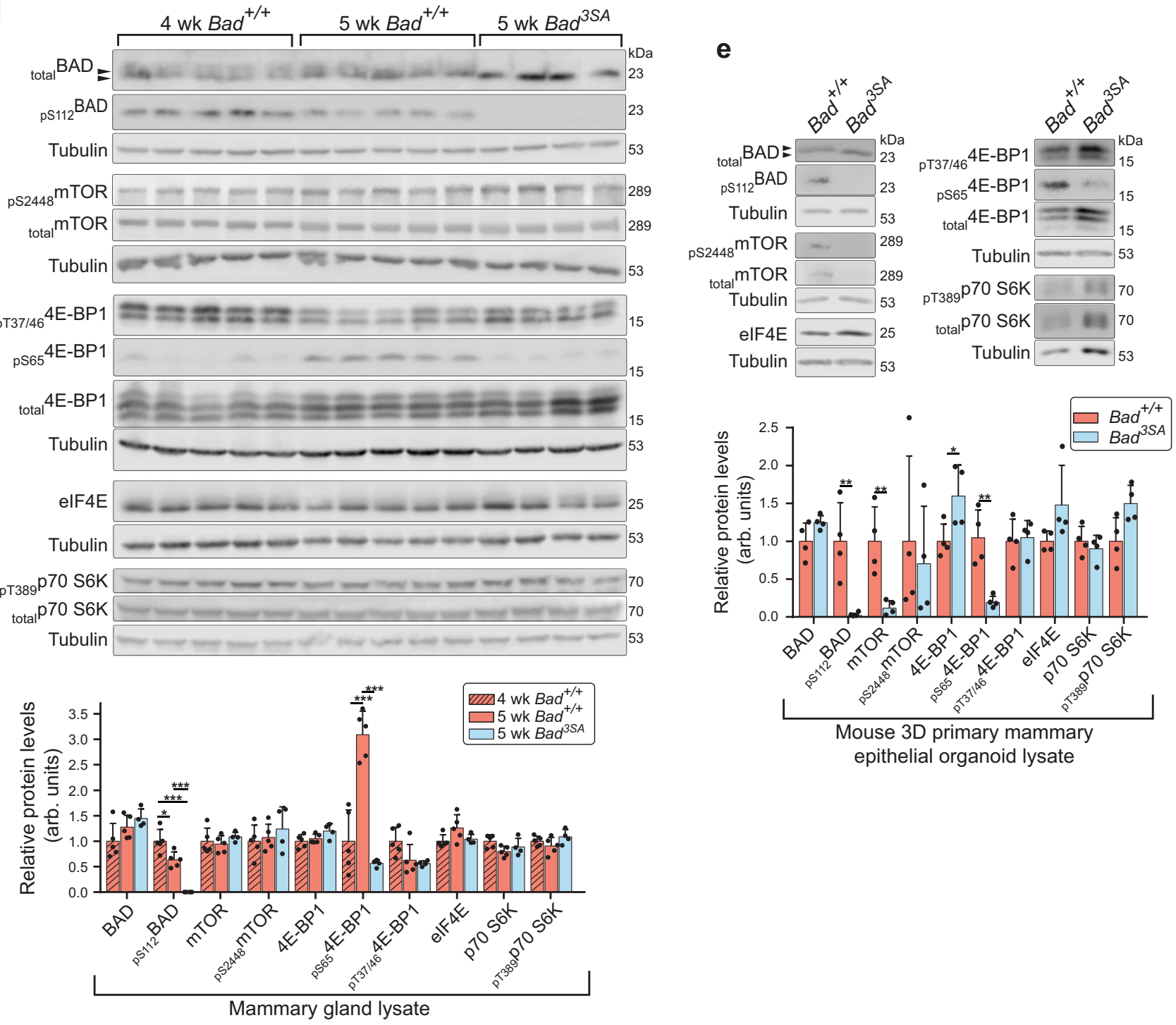

example, a pubertal delay phenotype occurs with in vivo depletion studies of mTORC1 ${ }^{62}$, which is consistent with our model where $\mathrm{Bad}^{3 S A}$ disrupts a key mTORC1 target, $4 \mathrm{E}-\mathrm{BP} 1$. Ductal pubertal delay has also been reported in FGFR-null mammary glands ${ }^{63}$, suggesting that BAD phosphorylation is downstream of FGFR signaling. This is consistent with our study, as FGF induces tubulogenesis in primary mouse 3D organoid cultures, and tubulogenesis is blocked by $\mathrm{Bad}^{3 S A}$. Furthermore, FGFR signaling responds to the pubertal hormones estrogen and progesterone ${ }^{64}$, providing an explanation for the pubertal-specific effect of $\mathrm{Bad}^{3 S A}$. Additionally, stromal depletion of Sharpin ${ }^{65}$ also phenocopies $\mathrm{Bad}^{3 S A}$. In this case, loss of Sharpin decreases ECM 
Fig. 5 RPPA screen identifies molecular markers that are altered in Bad ${ }^{3 S A}$. a Volcano plot of mammary gland protein and phosphoprotein differences between either different pubertal stages ( $4 \mathrm{wk}$ versus $5 \mathrm{wk}$ ) or different genotypes ( Bad $^{+/+}$versus Bad ${ }^{3 S A}$ ). $X$-axis is the fold change between groups ( Log $_{2}$ transformed) and the $Y$-axis is the $-\log _{10}$ adjusted $p$-value from Tukey-Kramer post hoc tests between groups (see Supplementary Data 2). The dotted horizontal line marks the significance alpha $(p$-value $=0.05)$. Dotted circles indicate the top 8 significant hits that represent 4 individual proteins or their phosphoproteins as shown in (b). b Total/phosphoprotein hits were ranked by order of significance (left to right on bar graph), based on differences between $5 \mathrm{wk} \mathrm{Bad}^{+/+}$(orange) and Bad $3 S \mathrm{SA}$ (blue) ( $p$-value $<0.01$, only RPPA validated antibodies). Bad $+/+4 \mathrm{wk} n=5, \mathrm{Bad}^{+/+} 5 \mathrm{wk} n=5, \mathrm{Bad}^{3 S A} 5 \mathrm{wk} n=5$ independent mice. Data are mean \pm SD. c Proportion of phosphorylated species for proteins asterisked in (b). Bad $+/+4 \mathrm{wk} n=5, \mathrm{Bad}^{+} /+5 \mathrm{wk} n=5, \mathrm{Bad}^{3 \mathrm{SA}}$ $5 \mathrm{wk} n=5$ independent mice. Data are mean \pm SD. d Top: western blots of mammary gland lysates for the top differentially expressed total/ phosphoproteins identified by RPPA. Validation lysates were generated from mammary glands independent from RPPA samples. Each lane contains lysates from independent mice $\left(\mathrm{Bad}^{+/+} 4 \mathrm{wk} n=5, \mathrm{Bad}^{+/+} 5 \mathrm{wk} n=5, \mathrm{Bad}^{3 S A} 5 \mathrm{wk} n=4\right)$. Black arrowheads highlight gel shift indicative of BAD phosphorylation. Bottom: quantitation of relative protein levels validated that pS112BAD and pS65-4E-BP1 are significantly decreased in Bad $35 A$ (blue). Data are mean \pm SD. e Top: western blots from mouse 3D branching organoid lysates probing top total/phosphoprotein hits identified in (b). Lysates were made from day 6 of organoid assays. Bottom: quantitation of relative protein levels show Bad $35 A$ (blue) had decreased pS112BAD, decreased pS65-4E-BP1 and increased levels of total 4E-BP1. Data are mean \pm SD of four independent experiments. For all $p$-values, ${ }^{\star \star \star} P<0.001,{ }^{\star \star} P<0.01,{ }^{\star} P<0.05$. Statistical test details and exact $p$ values are provided in Supplementary Data 4. Source data are provided in the Source data file.

collagen stiffness, diminishing integrin signaling. We speculate that by reducing the translation of focal adhesion components such as paxillin and actin, BAD ${ }^{3 S A}$ would similarly impair integrin function. Clearly, our data integrates a novel BAD/4E$\mathrm{BP} 1$ axis into known molecular pathways of mammary gland morphogenesis.

We demonstrate that non-P-BAD inhibits pubertal development by interfering with mRNA translation. Translation is controlled by the kinase complex mTORC1 and mTORC1 loss-offunction induces similar transient pubertal mammary gland delay $^{62}$. We, therefore, assessed whether Bad $^{3 S A}$ inhibits mTOR. Although $\mathrm{Bad}^{3 S A}$ primary $3 \mathrm{D}$ organoids decrease both total and P_S2448 mTOR levels (Fig. 5e), these differences are not recapitulated in either whole mammary glands or MCF10A 3D tubules (Fig. 5d, Supplementary Fig. 7g). Additionally, the mTORC1 downstream target p70-S6K is not differentially phosphorylated in any of the experimental models (Fig. 5d, e, Supplementary Fig. $7 \mathrm{~g}$ and Supplementary Data 2), suggesting mTORC1 is not the target of the Bad ${ }^{3 S A}$ defect. On the other hand, $\mathrm{Bad}^{3 S A}$ consistently disrupts regulatory phosphorylation of the translational inhibitor, $4 \mathrm{E}-\mathrm{BP} 1.4 \mathrm{E}-\mathrm{BP} 1$ is also classically regulated by $\mathrm{mTORC1}$ via sequential phosphorylation of T37, T46, and S65 $50,66,67$. Notably, phosphorylation of 4E-BP1 (T37/ 46 ) is not different between the genotypes, again, ruling out a direct role of mTORC1. Instead, Bad $^{3 S A}$ specifically blocks $4 \mathrm{E}$ BP1 only at its hyperphosphorylation site (S65). Taken together, these results suggest that $B a d^{3 S A}$ regulates $4 \mathrm{E}-\mathrm{BP} 1$ downstream of, or independent of, mTORC1. In a potentially similar scenario, RhoE regulates actin and focal adhesion assembly of NIH3T3 cells by inhibiting phosphorylation of 4E-BP1 on S65, independent of $\mathrm{mTOR}^{68}$. Thus, while the $\mathrm{mTOR} / 4 \mathrm{E}-\mathrm{BP} 1$ axis is well established, alternative 4E-BP1 kinases and phosphatases are known $^{66}$ and may be regulated by $\mathrm{Bad}^{3 S A}$. Candidate P-S65_4EBP1 kinases include GSK3 $\beta$, ERK1/2, PIM2, p38MAPK, CDK1, and CDK2 $2^{66,69,70}$. While Bad ${ }^{3 S A}$ mammary gland lysates show no differences in phosphorylation of regulatory sites in 3 of these kinases (GSK3 $\beta$, CDK1, or ERK1/2; Supplementary Data 2), the contribution of other unexplored kinases or phosphatases is unknown at this point. Indeed, this might explain why $4 \mathrm{E}-\mathrm{BP} 1$ phosphorylation is unaffected by mTOR inhibitors in some cancer cells ${ }^{71-73}$. The mechanism by which $\mathrm{BAD}^{3 \mathrm{SA}}$ inhibits $4 \mathrm{E}-$ BP1 hyperphosphorylation is speculative at this point. Non-P$\mathrm{BAD}$ is localized to mitochondria and enhances mitochondrial metabolism ${ }^{13,74}$ and GO analysis of mammary glands from this study, identify mitochondria and ATP synthase activity as differentially represented in Bad $^{3 S A}$ tissue (Supplementary Fig. $4 \mathrm{~d}$ ). Altered mitochondrial metabolism may additionally influence amino acid metabolism that is critical for protein synthesis.
Intriguingly, leucine depletion decreases mRNA translation in association with hypophosphorylated $4 \mathrm{E}-\mathrm{BP} 1^{75}$. Thus, further investigations will be needed to elucidate the molecular interactions whereby non-P BAD modulates mitochondrial metabolism, and whether this alters 4EBP-1 phosphorylation in the migrating pubertal mammary epithelial cell.

Bad3SA disrupts pubertal mammary gland development and alters cell migration. While stem cells are critical for mammary gland morphogenesis, $\mathrm{Bad}^{3 S A}$ does not appear to affect the stem/ progenitor pools. $\mathrm{Bad}^{3 S A}$ does not alter MRUs, which are capable of regenerating a functional mammary tree from a single stem cell $^{46}$. These MRUs serve as a source of differentiating luminal and myoepithelial cells and in line with this, the $B a d^{3 S A}$ mammary gland also has normal cell lineage proportions. Thus, Bad $^{3 S A}$ alters a morphogenetic process that is downstream of epithelial lineage commitment. Since epithelial cell motility is also critical for ductal elongation ${ }^{76}, \mathrm{Bad}^{3 S A}$-mediated defects in cell motility are likely the cause of the developmental delay. During the process of cell motility, local translation efficiently accumulates newly synthesized proteins at leading protrusions ${ }^{77,78}$. Inhibiting this local translation destabilizes nascent protrusions and diminishes cell motility in $2 \mathrm{D}$ assays ${ }^{23-25,56,79}$. Local translation products that are critical for cell migration include modulators of actin polymerization and adhesion complexes ${ }^{80,81}$. In fact, local enrichment of actin and actin-related proteins is required for collective elongation of mammary epithelial tubes ${ }^{82}$. In line with this our MS proteomic screen identified pubertalinduced differential protein expression in actin binding and focal adhesion proteins, and we validated that $\mathrm{BAD}^{3 \mathrm{SA}}$ protrusions are diminished for F-actin and paxillin. In particular, $\beta$-actin mRNA is locally translated near focal adhesions ${ }^{83}$ and interestingly, it is the newly synthesized $\beta$-actin that is preferentially used in focal adhesion maturation ${ }^{56}$. While global $\beta$-actin is less sensitive to cap-dependent translation perturbation ${ }^{84-88}$, this has recently been demonstrated to be cell type and stress dependent ${ }^{89-91}$. Indeed, during axon guidance, localized $\beta$-actin translation is associated with localized 4E-BP1 hyperphosphorylation ${ }^{92}$. Disruption of $\beta$-actin localized translation decreases cell protrusion stability, reduces focal adhesion maturation, and inhibits cell motility 56,93 , which similarly describe the $\mathrm{BAD}^{3 \mathrm{SA}}$ phenotype, suggesting that mammary epithelial cell migration requires compartmentalized protein synthesis of $\beta$-actin. Of course, $\beta$ actin is not the only locally translated mRNA that contributes to cell motility. Global screens and mRNA/protein quantitation of cell protrusions in MDA-MB-231 breast carcinoma cells established that many actin-associated protein mRNAs are translated at protrusions including Arp2/3 and alpha-actinin among others $^{23}$. These proteins are also depleted in $\mathrm{Bad}^{3 S A}$ mammary 
a

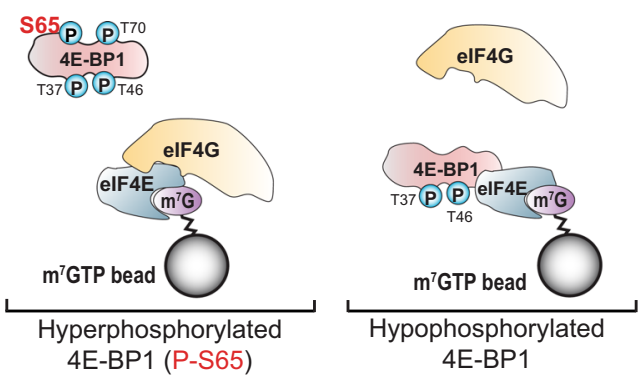

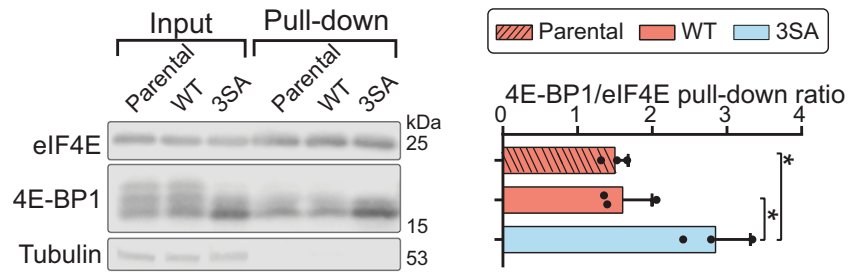
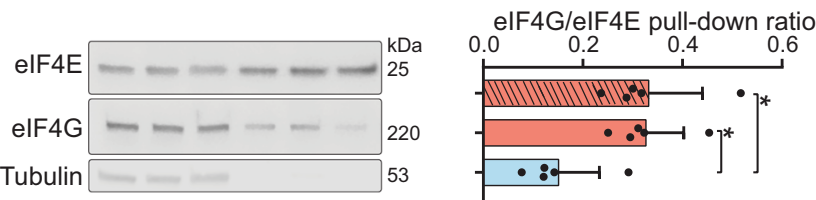

b
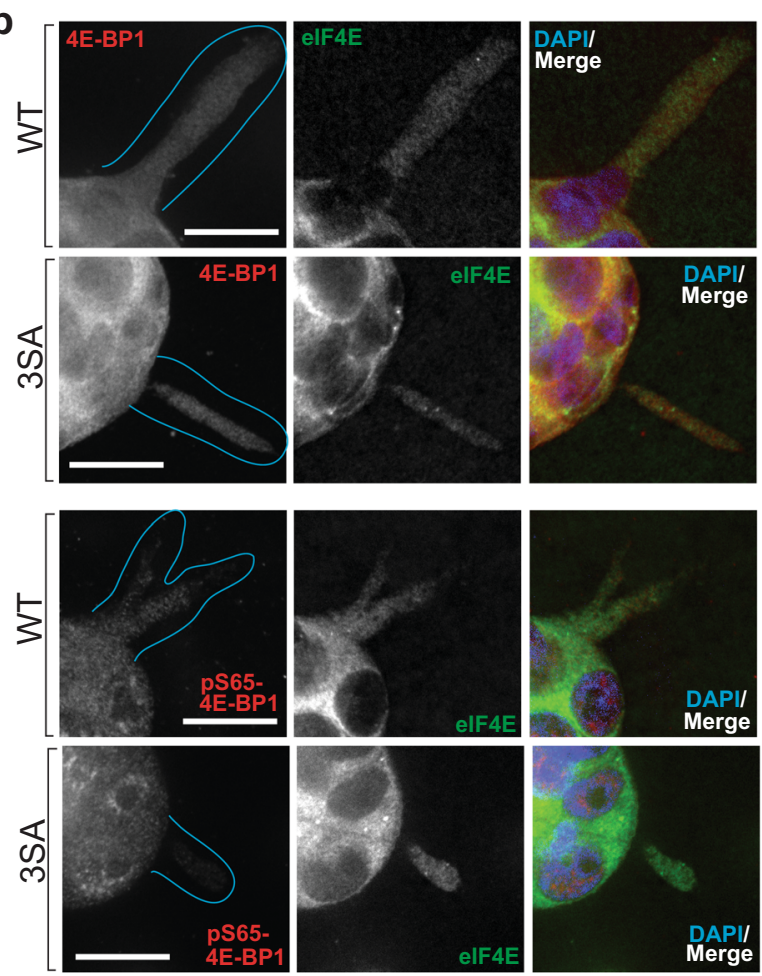

Protrusion outline
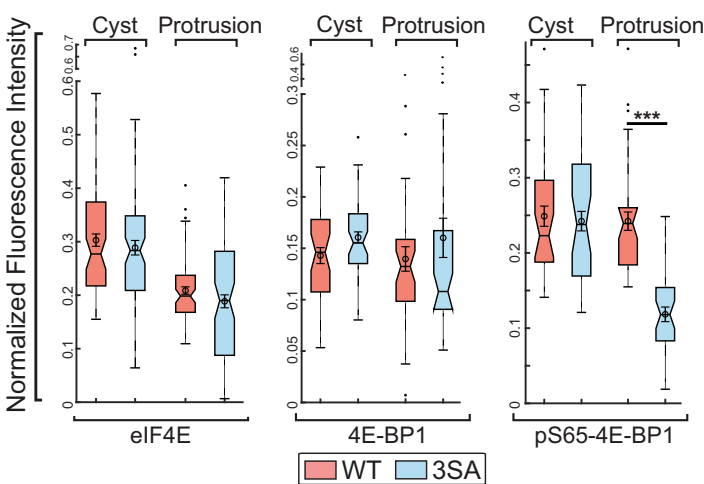

glands (Supplementary Data 1), supporting a general block in local translation. Unlike the 3D MCF10A tubulogenesis assay, 3D primary mouse organoid cultures do not depend on focal adhesions for migration. Elongation in these tubes is driven by intercalating migrating cells with compartmentalized Ras-PI3K activation and $\mathrm{F}$-actin polymerization in leading protrusions ${ }^{82}$. Whether this depends on localized translation is not known, although we propose this may be the case, since we did observe
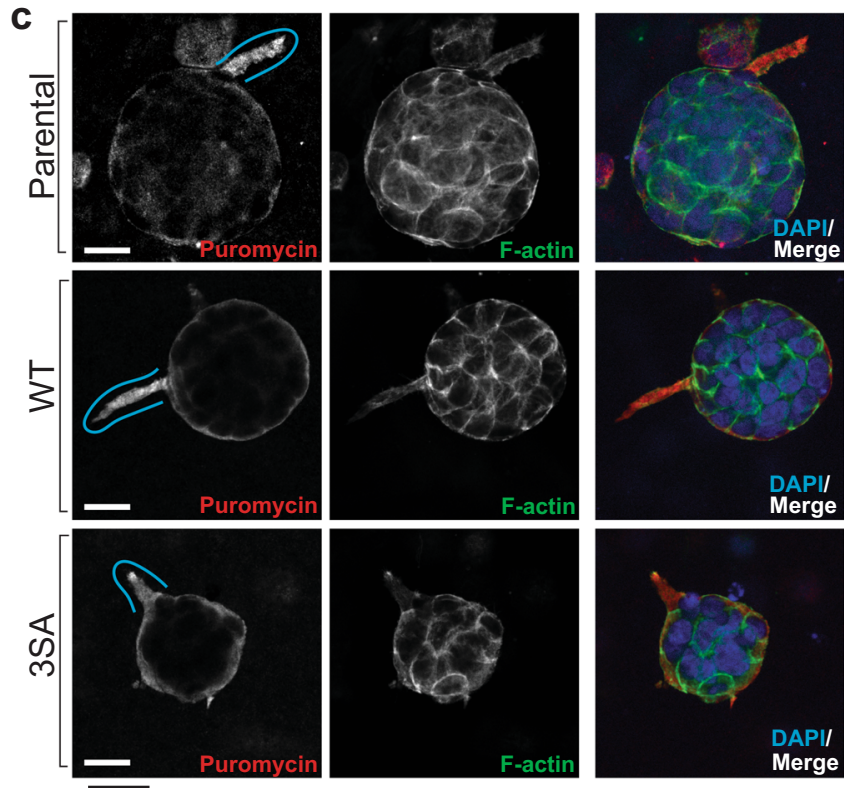

Protrusion outline

Puro-treated MCF10A tubulogenesis assay

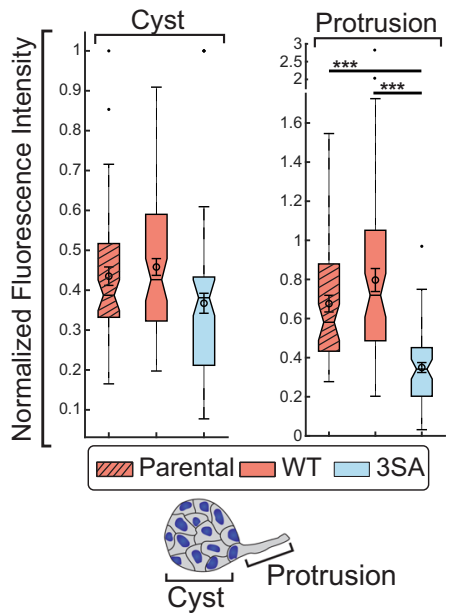

dysregulated 4E-BP1 phosphorylation and local translation in Bad $^{3 S A}$ 3D organoids. Thus, localized translation potentially contributes to in vivo cell motility during mammary gland ductal elongation, and our study suggests that this is regulated by BAD.

In summary, these results identify $\mathrm{BAD}$ as a regulator of pubertal gland development, affecting localized mRNA translation and cell migration. BAD is normally phosphorylated in the pubertal mammary gland when ductal migration is extensive but 
Fig. 6 3D MCF10A cysts from 3SA have defective localized mRNA translation. a Left: schematic for $m^{7} G T P$ pull-down assay to assess the interaction of elF4E with 4E-BP1 or elF4G. Middle: representative western blot from MCF10A 3D tubule lysates (day 7) from Parental, WT, 3SA showing levels of elF4E, $4 \mathrm{E}-\mathrm{BP1}$, and elF4G (Input). Lysates were subject to $\mathrm{m}^{7} \mathrm{GTP}$ pull-down and western blot shows levels of elF4E, 4E-BP1, and elF4G that were bound to $\mathrm{m}^{7} \mathrm{GTP}$ (Pull-down). Right: quantitation shows ratio of $4 \mathrm{E}-\mathrm{BP} 1$ or elF4G per elF4E recovered from the $\mathrm{m}^{7} \mathrm{GTP}$ pull-down. 3SA (blue) shows increased 4EBP1 and decreased elF4G interactions with elF4E. $n=4$ independent experiments. $\mathbf{b}$ Top: representative immunofluorescence images of cyst protrusions from WT and 3SA in early tubulogenesis assays (day 3) stained with anti-elF4E (green), either anti-4E-BP1 or anti-pS65-4E-BP1 (red) and DAPI (blue). The teal line is placed to outline subcellular protrusions subject to subsequent quantification analyses. Bottom: Tukey boxplots showing quantitation for normalized elF4E, 4E-BP1, and pS65-4E-BP1 normalized fluorescence intensity in either the cyst or subcellular protrusion. Only pS65-4E-BP1 showed decreased staining, specifically in protrusions of 3SA. WT and 3SA show similar elF4E and 4E-BP1 staining in the cyst and protrusions. WT $n=35,3 S A$ 37, from three independent experiments. c Top: representative immunofluorescence images of 3D MCF10A tubulogenesis assays treated with puromycin in culture, then processed for immunofluorescence and stained with anti-puromycin (red), phalloidin (F-actin, green) and DAPI (blue). Scale bars $=20 \mu m$. Bottom: Tukey boxplots for normalized cyst and protrusion puromycin intensity show decreased puromycin staining in Bad $35 A$ protrusions (blue). Parental $n=57$, WT $n=63,3 S A n=60$ from three independent experiments. For Tukey boxplots, constriction indicates median, notch indicates $95 \%$ confidence interval, box edges are 25th and 75th percentiles, whiskers show extreme data points, "outliers" plotted as black dots, overlaid circle, and error bars are the mean \pm SEM. For all $p$-values, ${ }^{\star \star \star} P<0.001,{ }^{\star \star} P<0.01,{ }^{\star} P<0.05$. Statistical test details and exact $p$-values are provided in Supplementary Data 4 . Source data are provided in the Source data file.

is not phosphorylated in the nulliparous adult. Whether BAD phosphorylation is aberrantly reactivated in breast carcinogenesis potentially facilitating metastasis, is unclear at this point. Altogether, this study provides a framework with which to query both normal and neoplastic mammary gland processes and link a noncanonical role of $\mathrm{BAD}$ and translation to mammary gland development and cancer pathophysiology.

\section{Methods}

Mouse line and breeding. Animal procedures were performed in accordance with the guidelines and regulations set forth by the Canadian Council on Animal Care and approved by the University of Alberta Health Sciences 2 Animal Care and Use Committee (Protocol\# AUP00000386). All mouse strains were in the C57BL/6J background and have been previously described ${ }^{7,8,10}$.

\begin{abstract}
Whole-mounts imaging and morphological analysis. Whole mount (WM) carmine staining of abdominal mammary gland \#4 was done as described ${ }^{94}$. WMs slides were converted into digital images using an Epson Perfection scanner with a resolution of $2400 \mathrm{dpi}$, resulting in $10.5 \mu \mathrm{m}$ pixel size RGB images. Image gamma was changed to 0.45 to contrast the epithelial tree against the stromal background. Morphological analysis was carried out on MATLAB (MathWorks). Terminal end buds (TEBs) on the leading edge and epithelial tree origin (nipple) were visually determined. To segment the epithelial tree, the RGB images were first converted to grayscale using principal component analysis transform. Contrast enhancement was then employed on the grayscale image using contrast-limited adaptive histogram equalization. Background image was then computed using a wide Gaussian (standard deviation 20 pixels) and subtracted from the contrast-enhanced image. The resultant image was binarized using Otsu's method in multithresh function. Additional morphological operations were carried out if necessary, to ensure the binary image matched the epithelial tree. From this epithelial tree binary image, boundary function (default shrink factor 0.5 ) was used to calculate epithelial tree area. Ductal extension was obtained from the longest distance between the nipple (tree origin) and tree boundary (in all whole mounts, ductal extension was towards the leading edge). The binary image was then skeletonized, and primary branches computed from the skeleton branchpoints. Manual refinement of the primary branches was performed to correct for artifacts such as detected 'branchpoints' due to independent ducts overlap. Dirichlet tessellation was computed using the branch points to determine the Voronoi polygon area occupied by each primary branch point within the epithelial tree area. For leading edge to lymph node (LN) distance measurements, LN, which was typically the darkest feature in the whole-mounts images, was segmented by looping though different threshold levels of multithresh function until a perfect LN boundary was obtained. The distance was computed from the resultant LN boundary centroid to the leading edge. The distance was considered positive if the epithelial leading edge was beyond LN centroid, other wise, negative.
\end{abstract}

Transplantation assay. The transplant assay was performed as described ${ }^{95}$ Briefly, mammary gland epithelial fragments from 8-wk donor mice were implanted into cleared fat pads of mammary gland \#4 of 3-wk recipient mice (Schematic Fig. 2d). Recipient glands were harvested 6 to 7 -weeks post surgery and WMs carmine stained as aforementioned. WMs slides were imaged and donor epithelial tissue outgrowth assessed. Cleared, non-transplanted fat pads were used as controls for clearance efficiency of endogenous epithelium.
Dissociation of mouse mammary epithelial cells and flow cytometry analysis. 8 -wk mouse mammary glands were minced using a sterile blade and subsequently digested in dissociation medium (20 mg Collagenase A and $10 \mathrm{mg}$ Dispase II in $10 \mathrm{ml} \mathrm{DMEM} / \mathrm{F} 12)$ for $3 \mathrm{~h}$ at $37^{\circ} \mathrm{C}$ with $120 \mathrm{rpm}$ shaking. The dissociated tissue was spun down at $450 \times g$ for $10 \mathrm{~min}$ and then the supernatant was discarded. Preparation of a single cell suspension was done as detailed ${ }^{45}$. EasySep ${ }^{\text {TM }}$ Mouse Epithelial Cell Enrichment Kit II (Stem Cell Technologies) was used to exclude non-epithelial (lineage-negative) cells following the manufacturer's instructions. For flow cytometry staining, cells were aliquoted for controls (unstained, singlestained, "fluorescence minus one" controls) and samples. Control and sample cells were accordingly incubated on ice for $10 \mathrm{~min}$ with PE-conjugated anti-CD24 (Stem Cell Technologies), FITC-conjugated anti-CD49f (Stem Cell Technologies) and Alexa Fluor ${ }^{\circledast}$ 647-conjugated anti-EpCAM (BD Biosciences). The dual combination of these surface markers (See Supplementary Fig. 6) were shown to have the least tendency of contaminating gated basal cells with non-epithelial cells, especially in the C57BL/6J background ${ }^{96}$, which is the strain of mice used in our study. Flow cytometry was performed using the BD Accuri ${ }^{\mathrm{TM}} \mathrm{C} 6$ and analyzed with FlowJo (version 10). Cell lineages were determined after pre-gating for single cells (Supplementary Fig. 6)

Isolation of primary mouse mammary organoids. Mammary organoids were prepared as described ${ }^{32}$. Briefly, mammary glands from 5-wk old mice were harvested and immediately minced with a scalpel ( 40 times) under a laminar flow hood and digested for $30-40 \mathrm{~min}$ at $37^{\circ} \mathrm{C}$ with $120 \mathrm{rpm}$ shaking in $10 \mathrm{~mL}$ collagenase solution per mouse (Collagenase solution: $2 \mathrm{mg} / \mathrm{mL}$ collagenase (Sigma Cat\# C2139), $2 \mathrm{mg} / \mathrm{mL}$ trypsin (Sigma Cat\# T0303), 5\% fetal bovine serum (FBS), $5 \mu \mathrm{g} / \mathrm{mL}$ insulin (Sigma Cat\#I0516), and $50 \mu \mathrm{g} / \mathrm{mL}$ gentamicin (ThermoFisher Cat\# 15710064) in DMEM/F12. Epithelial organoids were subsequently isolated through differential centrifugation and frozen in 10\% DMSO, 20\% FBS, and 70\% DMEM/ F12 freezing media for future use.

Primary mouse organoid branching assay. Mammary organoids were thawed, and freezing medium washed off with DMEM/F12 (2 times, $1200 \mathrm{rpm}$ for $1 \mathrm{~min}$ ). $50 \mu \mathrm{l}$ of organoid suspension was aspirated onto a petri dish and the number of organoids counted under a tabletop microscope. From this tally, organoid density was adjusted to 4 organoids per $\mu$ l. For $3 \mathrm{D}$ gel preparation, rat tail collagen-I (Corning Cat\# 354236) was neutralized with $1 \mathrm{~N} \mathrm{NaOH}$ and 10× DMEM (217:25:8 volume ratio, respectively), adjusted to $3 \mathrm{mg} / \mathrm{mL}$ final concentration (using DMEM/F12) and incubated for $1 \mathrm{~h}$. Organoids were then embedded to a final density of 2 organoids per $\mu \mathrm{l}$ in pre-thawed 3 parts volume growth factor reduced Matrigel (Corning Cat\# 354230) and 7 parts volume collagen-I solution, a ratio previously determined to be optimal for mouse branching organoids assay ${ }^{31,32}$. The organoid-gel suspension was gently plated in wells of a 12 -well plate $(50-100 \mu \mathrm{l}$ per well), placed on top of a heating block $\left(37^{\circ} \mathrm{C}\right)$ to aid with gelation for a few minutes before placing the plate in a cell incubator $\left(5 \% \mathrm{CO}_{2}, 37^{\circ} \mathrm{C}\right)$ for $45 \mathrm{~min}$. Pre-warmed branching organoid medium (DMEM/F12 supplemented with $1 \times$ penicillin/ streptomycin, $1 \times$ insulin-transferrin-selenium-X (GIBCO Cat\# 51500), $10 \mathrm{ng} / \mathrm{mL}$ EGF (Peprotech Cat\# AF100-15) and 2.5 nM FGF2(Sigma Cat\# F0291)) was then added and replenished every 3 days.

MCF10A tubulogenesis assay. MCF10A cells were maintained in MCF10A growth medium ${ }^{97}$ (DMEM/F12 supplemented with $5 \%$ horse serum, $20 \mathrm{ng} / \mathrm{mL}$ EGF (Peprotech Cat\# AF100-15), 0.5 $\mu \mathrm{g} / \mathrm{mL}$ Hydrocortisone (Sigma Cat\# H-0888), $100 \mathrm{ng} / \mathrm{mL}$ Cholera toxin (Sigma Cat\# C-8052), $10 \mu \mathrm{g} / \mathrm{mL}$ insulin (Sigma Cat\# I1882 ) and $1 \times$ penicillin/streptomycin). Stable ectopic expression of wild-type BAD (WT) or phosphomutant (3SA) was done in MCF10A $B A D^{-/-}(B A D$ knockout $)$ 
a
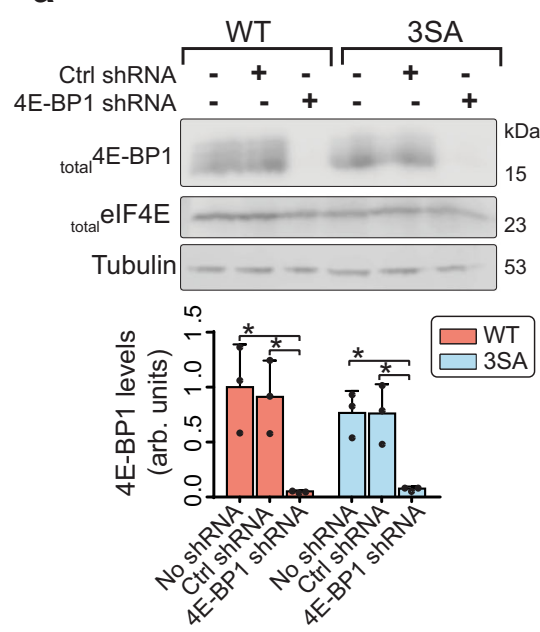

b Inset shown
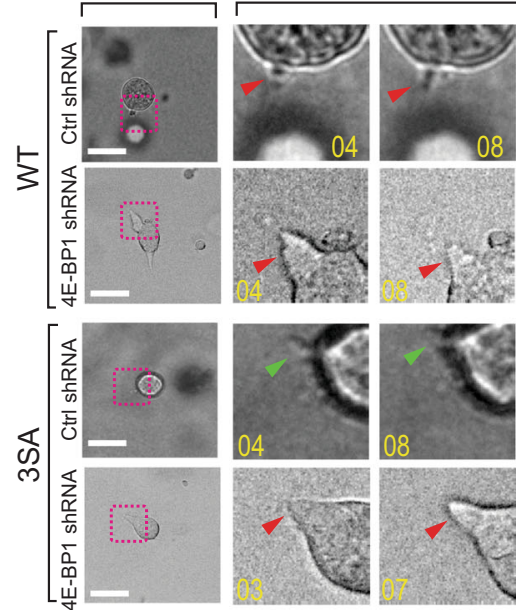

Time-lapse $(\mathrm{h})$

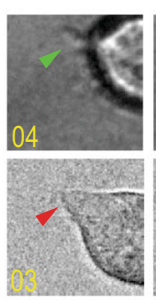

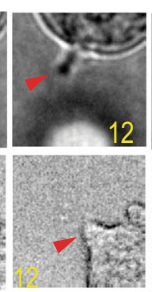
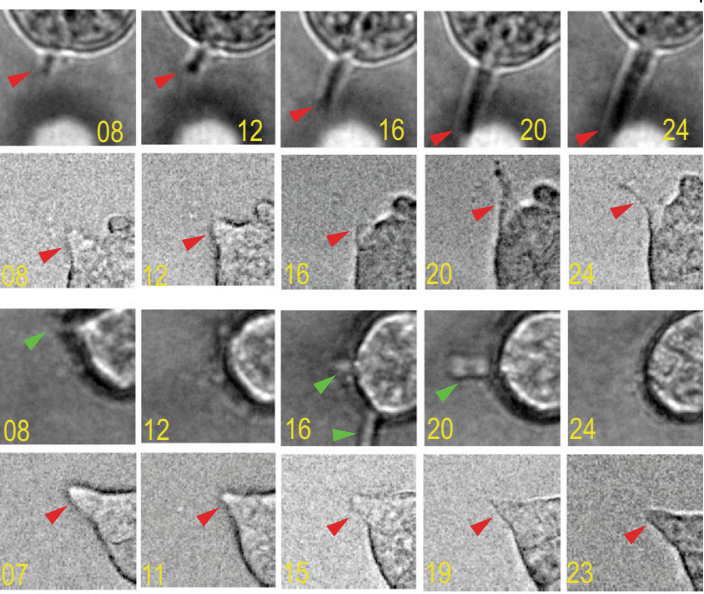
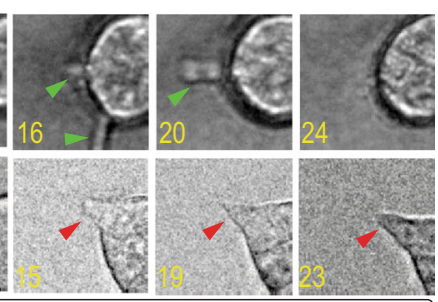

- Stable protrusion $>$ Unstable protrusion
C

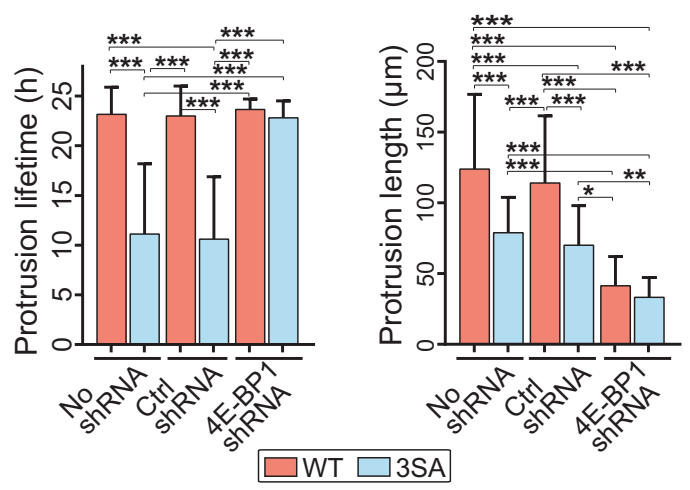

e

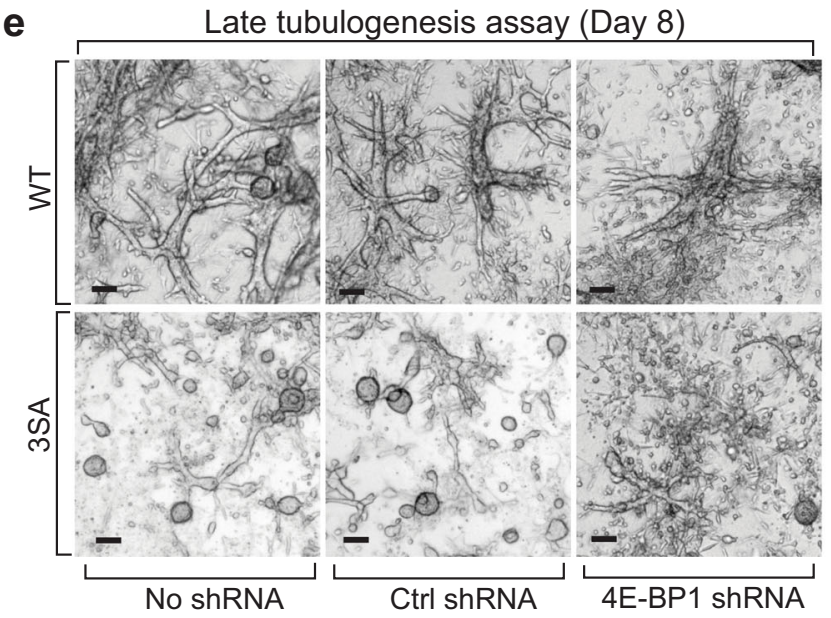

g

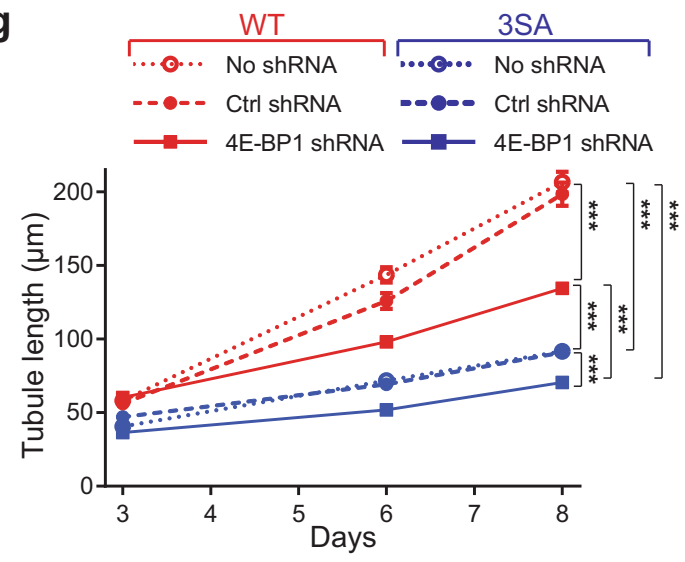

cells we previously described ${ }^{13}$. For 3D tubulogenesis assay gel preparation, bovine collagen-I (Advanced BioMatrix Cat\# 5005) was neutralized and incubated for $1 \mathrm{~h}$ as detailed above for branching organoid assay. MCF10A single cells were then embedded ( 50 cell per $\mu \mathrm{l})$ in pre-thawed 1 parts volume growth factor reduced Matrigel (Corning Cat\# 354230) and 9 parts volume collagen-I solution $(1 \mathrm{mg} / \mathrm{mL}$ final concentration). The cell-gel suspension was gently plated in wells of a 12 -well plate $\left(50-100 \mu \mathrm{l}\right.$ per well) placed on top of a heating block $\left(37^{\circ} \mathrm{C}\right)$ to aid with gelation for a few minutes before placing the plate in a cell incubator $\left(5 \% \mathrm{CO}_{2}\right.$, $37^{\circ} \mathrm{C}$ ) for $45 \mathrm{~min}$. Pre-warmed MCF10A growth medium was then added and replenished every 3 days.

m7GTP pull-down assay. Whole gels containing MCF10A cysts and tubules were harvested on day 7 of the tubulogenesis assay in pull-down assay lysis buffer $(20$
$\mathrm{mM}$ Tris- $\mathrm{HCl}, 100 \mathrm{mM} \mathrm{NaCl}, 25 \mathrm{mM} \mathrm{MgCl} 2,0.5 \% \mathrm{NP}-40$, freshly added protease, and phosphatase inhibitors (Roche Cat\# 5056489001 and Cat\# 4906837001, respectively)). Protein lysate was collected from the supernatant after $10,000 \times g$ 20 min centrifugation at $4{ }^{\circ} \mathrm{C}$. To assess eIF4E:4E-BP1 association, for each sample, $20 \mu \mathrm{l}$ of a $80 \%$ slurry of immobilized $\gamma$-aminophenyl- $\mathrm{m}^{7}$ GTP beads (linked via a C10-spacer, Jena Bioscience Cat\# AC-155) was washed three times in lysis buffer $(500 \times g$ for $30 \mathrm{~s})$ and incubated overnight at $4{ }^{\circ} \mathrm{C}$ with the protein lysate with gentle rotation. Beads were then gently washed with the pull-down assay buffer ( 3 times, $500 \times g$ for $30 \mathrm{~s}$ ), bound proteins were eluted and analyzed on a western blot.

SUnSET assay. Mouse branching organoid and MCF10A tubulogenesis gels were incubated with $10 \mu \mathrm{g} / \mathrm{mL}$ puromycin (Sigma Cat\# P8833) for $30 \mathrm{~min}$. No puromycin and $15 \mathrm{~min}$ pre-treatment with $50 \mu \mathrm{g} / \mathrm{mL}$ cycloheximide (Sigma Cat\# 
Fig. 7 3SA-mediated defects in protrusions and tubuologenesis are dependent on 4E-BP1. a Top: representative western blots assessing 4E-BP1 levels in MCF10A WT and 3SA cell lines stably expressing 4E-BP1 shRNA. Lysates were generated from 3D tubulogenesis assays of indicated cell lines expressing either no shRNA (-), control non-specific shRNA ( + Ctrl shRNA), or 4E-BP1 shRNA (+ 4E-BP1 shRNA) and blots were probed for 4E-BP1 and elF4E. Bottom: quantitation shows decreased 4E-BP1 protein levels in 4E-BP1 shRNA-expressing lysates (4E-BP1 shRNA). Data is mean \pm SD from three independent experiments. b Representative bright-field time-lapse images for 3D tubulogenesis assays of WT (upper 2 panels) and 3SA (lower 2 panels) cells with either control knockdown (Ctrl shRNA) or 4E-BP1 knockdown (4E-BP1 shRNA). Imaging was started on day 3 of tubulogenesis assays. Yellow numbers in insets indicate timepoint (hrs) during imaging (for complete time-lapse images, see Supplementary Movie 3). Red arrowheads indicate stable protrusions and green arrowheads indicate unstable protrusions. Scale bars $=100 \mu \mathrm{m}$. WT Ctrl shRNA $n=31$, WT 4E-BP1 shRNA $n=26,3 S A$ Ctrl shRNA $n=31,3 S A$ 4E-BP1 shRNA $n=27$, from three independent experiments. c Quantitation of average protrusion lifetime shows that 3SA-destabilized protrusions are rescued by $4 \mathrm{E}-\mathrm{BP} 1$ knockdown (blue $+4 \mathrm{E}-\mathrm{BP} 1$ shRNA). WT no shRNA $n=37$, WT Ctrl shRNA $n=31, \mathrm{WT} 4 \mathrm{E}-\mathrm{BP} 1$ shRNA $n=26,3 \mathrm{SA}$ no shRNA $n=37$, 3SA Ctrl shRNA $n=31,3 S A 4 E-B P 1$ shRNA $n=27$, from three independent experiments. Data are mean \pm SD. d Quantitation of average protrusion length shows that 4E-BP1 knockdown decreases protrusion length in both WT and 3SA (orange and blue + 4E-BP1 shRNA). WT no shRNA $n=$ 37, WT Ctrl shRNA $n=31$, WT 4E-BP1 shRNA $n=26$, 3SA no shRNA $n=37$, 3SA Ctrl shRNA $n=31$, 3SA 4E-BP1 shRNA $n=27$, from three independent experiments. Data are mean \pm SD. e Representative bright-field images for 3D tubulogenesis assays on day 7 of WT (upper) or 3SA (lower), expressing no shRNA, Ctrl shRNA or 4E-BP1 shRNA. Scale bars $=100 \mu \mathrm{m}$. Fields of view for WT $n=16,3 \mathrm{SA} n=16$ from three independent experiments. $\mathbf{f}$ Percentage of cysts with branches over time for WT (red) or 3SA (blue). Line plots (mean \pm SD) show 3SA-mediated low percentage of branching cysts is increased by 4E-BP1 knockdown (blue solid line). Percentage of branching cysts in WT is also increased by 4E-BP1 knockdown (red solid line). Fields of view analyzed used for all conditions, $n=16$. $\mathbf{g}$ Quantitation of mean tubule length (mean \pm SEM) for WT (red) or 3SA (blue). Line plots show 4E-BP1 knockdown diminishes mean tubule length in WT 3D tubules (red solid line). Three independent experiments, 2 replicates per experiment. For number of tubules, WT no shRNA, control shRNA, and 4E-BP1 shRNA $n=132,124$ and 146, respectively. 3SA no shRNA, control shRNA, and 4E-BP1 shRNA $n=135,142$, and 135, respectively. For all $p$-values, ${ }^{\star \star \star} P<0.001,{ }^{\star \star} P<0.01,{ }^{\star} P<0.05$. Statistical test details and exact $p$-values are provided in Supplementary Data 4 . Source data are provided in the Source data file.

C7698) were used as controls. Puromycinylated polypeptides were detected by western blot or immunofluorescence assays (see "Western blotting" and "Immunofluorescence" sections below).

Cap-translation reporter gene assay. Bicistronic fluorescent reporter gene plasmid pYIC (gift from Dr. Han Htun ${ }^{98}$, Addgene plasmid Cat\# 18673) with capdependent EYFP and IRES-dependent ECFP translation was used. MCF10A cells were electrotransfected using Amaxa nucleofector (program T020) and Lonza nucleofector Kit L. Cells were allowed to recover overnight and subsequently used in normal MCF10A tubulogenesis assays.

4E-BP1 knockdown. pLKO.1-puromycin vectors containing control shRNA (gift from Dr. David Sabatini ${ }^{99}$, Addgene plasmid Cat\# 1864) or 4E-BP1 shRNA (gift from Dr. Tommy Alain ${ }^{100}$, Sigma Cat\# TRCN0000040203) were packaged using MISSION $^{\circledR}$ Lentiviral Packaging Mix kit (Sigma Aldrich Cat\# SHP001) according to manufacturer's protocol. WT or 3SA MCF10A cells were infected with the lentivirus particles and selected using puromycin. Stable 4E-BP1 knockdown was confirmed using western blots (Fig. 7a).

BAD immunoprecipitation. Cells were treated as indicated and lysed in $1 \%$ CHAPS buffer (1\% CHAPS, $150 \mathrm{mM} \mathrm{NaCl}, 50 \mathrm{mM}$ Tris pH 7.4, 2 mM EDTA pH 8.0) supplemented with freshly added protease and phosphatase inhibitors. Lysates were incubated with anti-BAD antibodies $(1.5 \mathrm{~h})$ and recovered with Protein A Sepharose beads (Abcam, Cat\# ab193256).

Western blotting. Mammary gland lysates were generated as described for RPPA lysates, below. Mouse branching organoids and tubulogenesis lysates were made by aspirating the gels 5 times in lysis buffer (27-gauge needle. Lysis buffer: 1\% NP 40, $150 \mathrm{mM} \mathrm{NaCl}, 50 \mathrm{mM}$ Tris-HCL pH 7.6, 5 mM EDTA, 1 mM EGTA, freshly added protease and phosphatase inhibitors) and soluble protein lysates were collected from the supernatant after $14,000 \times g 20 \mathrm{~min}$ centrifugation at $4^{\circ} \mathrm{C}$. Lysates were resolved on SDS-PAGE gels and transferred to PVDF membranes. Mouse or rabbit primary antibodies were used for western blots (Supplementary Data 4). HRP and IRDye-coupled secondary antibodies were used and scanned using Odyssey LICOR Fc imager (LI-COR Biosciences) in the chemiluminescence, $700 \mathrm{~nm}$ and 800 $\mathrm{nm}$ channels. Band intensities were quantified with Image Studio ${ }^{\text {pw }}$ version 5.2 (LICOR Biosciences), which applies a local background subtraction determined for each band. All phosphorylation status was normalized to corresponding total protein. Uncropped blots are provided in the Source Data file.

Immunofluorescence. $100 \mu \mathrm{m}$ thick cryosections were cut from OCT compound (ThermoFisher Cat\# 23730572) embedded mammary glands or 3D gels which had been fixed (4\% PFA) and stored in $-80^{\circ} \mathrm{C}^{32}$. The sections were washed with PBS $(2 \times, 10 \mathrm{~min})$, quenched with $50 \mathrm{mM} \mathrm{NH}_{4} \mathrm{Cl}(30 \mathrm{~min})$ and permeabilized with $0.5 \%$ Triton X-100 (30 min). For staining, slides were blocked (3\% BSA in PBS, $1 \mathrm{~h}$ ) and incubated with mouse or rabbit primary antibodies (Supplementary Data 4). AlexaFluor-488, Cy3 or Alexa-Fluor 647 tagged anti-rabbit and anti-mouse secondary antibodies were used. Depending on the experiment, phalloidin Alexa-Fluor-555 or
Alexa-Fluor-647 (Invitrogen) were used to stain actin. Nuclei were stained with DAPI.

Imaging. Mouse branching organoids and MCF10A tubulogenesis 3D gels time lapse imaging was done in brightfield (Zeiss AxioObserver.Z1 Microscope, $\times 20$ air objective, 0.85 numerical aperture) on indicated days. All immunofluorescence imaging was acquired with Volocity software (PerkinElmer, USA) using a $\times 20$ oil immersion objective on WaveFx spinning-disk microscope (Quorum Technologies, ON, Canada). The microscope was set up on an Olympus IX-81 inverted stand (Olympus, Japan), equipped with EM-CDD camera (Hamamatsu, Japan).

Image intensity analysis. Image intensity segmentation and analysis for the 3D gel immunofluorescence images was done as described ${ }^{101}$. Briefly, channel intensity was corrected for non-uniform background. Mean intensity or intensity ratios were then calculated within the defined protrusion or body mask. For SUnSET assay images, the body region was restricted to $10 \mu \mathrm{m}$ around the body mask (Supplementary Fig. 9c) since the body central region was mostly devoid of puromycin intensity in all assays and genotypes. To quantify localized translation, we computed the ratio of puromycin intensity in the protrusion region over a size-matched region within the cyst body (Supplementary Fig. 9c).

Mass spectrometry and RPPA lysates screening. Using five independent mice for each screen and each group, mammary gland lysates from 5-wk Bad ${ }^{+/+}$and $\mathrm{Bad}^{3 S A}$ animals along with 4 -wk $\mathrm{Bad}^{+/+}$were generated (3 groups, 2 screens, total mice $=30)$. The \#4 mammary glands were harvested and immediately snap frozen in liquid nitrogen after lymph node removal. Samples were then lysed with a hand homogenizer (VWR Cat\# 47747-370). The lysis buffer for mass spectrometry (MS) samples was: $1 \% \mathrm{NP} 40,150 \mathrm{mM} \mathrm{NaCl}, 50 \mathrm{mM}$ Tris-HCL pH 7.6, freshly added protease and phosphatase inhibitors (Roche Cat\# 5056489001 and Cat\# 4906837001, respectively). The lysis buffer for RPPA samples was: $1 \%$ Triton X100, $50 \mathrm{mM}$ HEPES, pH 7.4, $150 \mathrm{mM} \mathrm{NaCl}, 1.5 \mathrm{mM} \mathrm{MgCl} 2,1 \mathrm{mM}$ EGTA, $100 \mathrm{mM}$ $\mathrm{NaF}, 10 \mathrm{mM}$ Na pyrophosphate, $1 \mathrm{mM} \mathrm{Na}_{3} \mathrm{VO}_{4}$, freshly added protease and phosphatase inhibitors (Roche Cat\# 5056489001 and Cat\# 4906837001, respectively). Soluble protein lysate was collected from the supernatant after $16,000 \times g$ 20 min centrifugation at $4{ }^{\circ} \mathrm{C}$. RPPA sample lysates were then diluted to $1 \mu \mathrm{g} / \mu \mathrm{l}$ (using 4X sample buffer: $40 \%$ glycerol, $8 \%$ SDS, 0.25 M Tris-HCL, pH 6.8 and $10 \%$ $\beta$-mercaptoethanol) and submitted to the MD Anderson RPPA Core Facility (University of Texas) for screening and initial analysis.

For mass spectrometry analysis, homogenates $(20 \mu \mathrm{g}$ of protein per sample) were run on $10 \%$ sterile-filtered SDS polyacrylamide gels, and subject to in-gel trypsin digestion ${ }^{102}$. Whole gel-lanes were excised using a scalpel and sectioned into 10-11 bands, each of which was further sectioned into $1 \mathrm{~mm}$ cubes. Cubes corresponding to an individual band were placed in a 96-well plate and subject to trypsinization. Extracted peptides from each well were concentrated and resuspended in $60 \mu \mathrm{L}$ of $0.2 \%$ formic acid in HPLC-grade water. Peptides were analyzed by LC-MSMS using a Thermo Easy nLC-1000 in tandem with a QExactive benchtop orbitrap mass spectrometer. $5 \mu \mathrm{L}$ of sample from each well was subject to a 75 -min gradient $(0-45 \%$ buffer $\mathrm{B}$; buffer $\mathrm{B}=0.2 \%$ formic acid in acetonitrile) on a $2 \mathrm{~cm}$ Acclaim 100 PepMap Nanoviper C18 trapping column with 


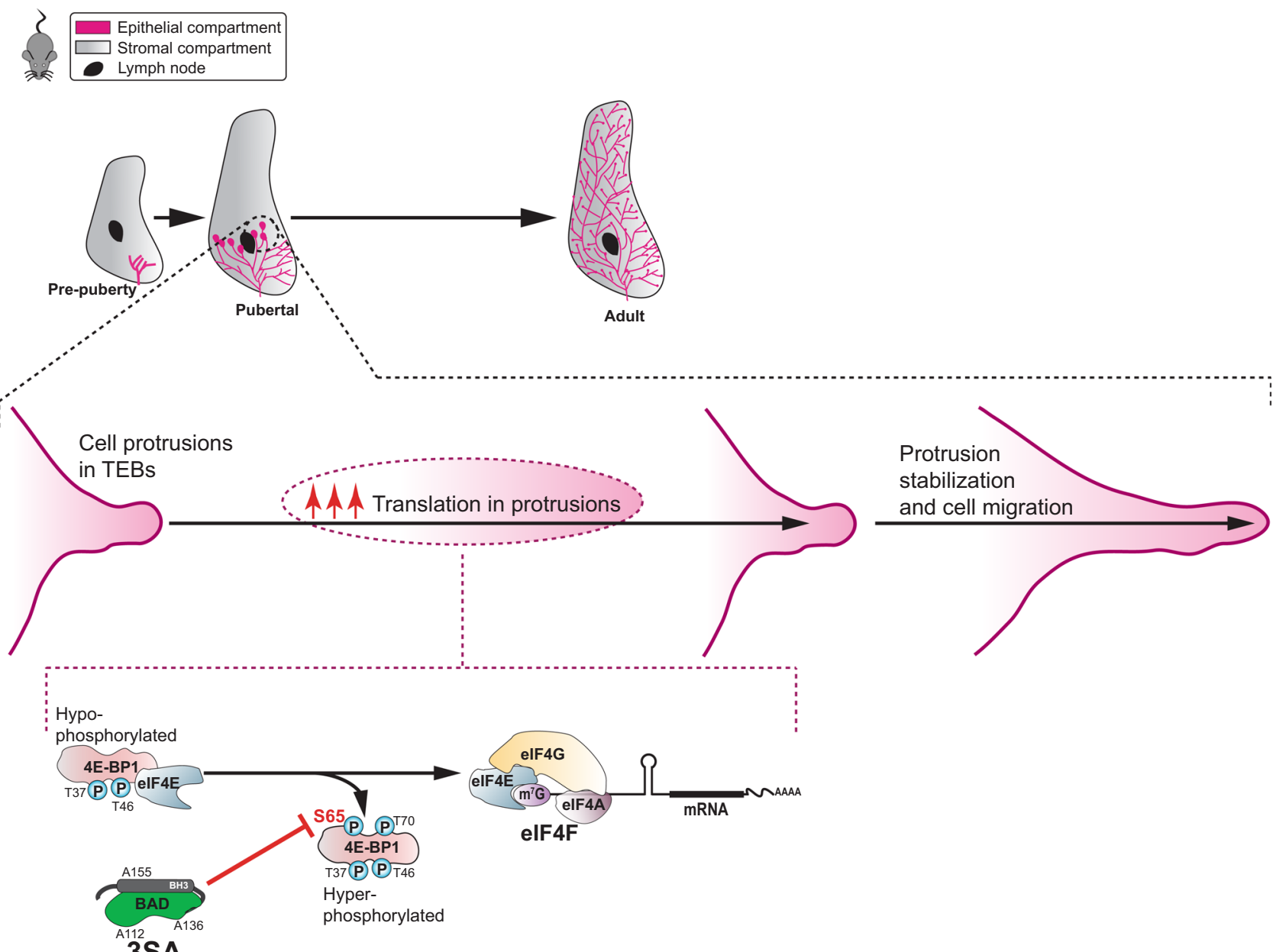

Non-phosphorylated BAD

inhibits pubertal gland morphogenesis

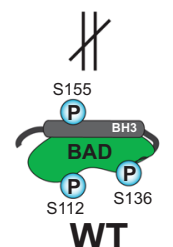

WT BAD is normally phosphorylated

and permissive for

pubertal gland morphogenesis

Fig. 8 Schematic model for the role of BAD in normal pubertal mammary development. BAD is normally phosphorylated in the pubertal mammary gland and this is permissive for $4 \mathrm{E}-\mathrm{BP} 1$ hyperphosphorylation and subsequent upregulation of localized translation for efficient cell migration and epithelial tree elongation. Preventing BAD phosphorylation (3SA) inhibits hyperphosphorylation of $4 \mathrm{E}-\mathrm{BP} 1$ that impairs cell migration and tree elongation.

a New Objective PicoChip reverse-phase analytical LC column, with spray voltage set to $2700 \mathrm{~V}$.

Mass spectrometry data processing. Raw data files comprising an entire gel lane were grouped and searched using Proteome Discoverer (PD) 1.4.1.14's SEQUEST search engine using a reviewed, non-redundant complete Mus musculus proteome retrieved from UniprotKB on October 16, 2015 ${ }^{102}$. Magellan storage files from all $n=15$ samples were opened in unison using the PD 1.4.1.14 software package, with data filtered to show only proteins identified with at least 2 medium confidence peptides (FDR $<0.05$ per peptide). Relative protein abundance was determined using proteins' extracted ion chromatograms (EICs) using PD 1.4.1.14's 'Precursor Ion Areas' module, in relation to the summation of all EICs from a given sample. Data were exported to Microsoft Excel.

Hierarchical clustering and random forest classification. Both MS and RPPA protein profile unsupervised hierarchical clustering was performed on MATLAB (clustergram function). Samples distance metric was set to correlation, and average distance between all pairs of objects in any two clusters was used to create dendrograms agglomerative hierarchical cluster tree. All total/phosphoproteins in RPPA were analyzed. For MS protein profiles, proteins with zero ion intensity were assigned half of the global minimum ion intensity in the dataset. Then, for each group, proteins that initially had zero ion intensity in more than two samples were filtered out (799 proteins left).

Random forest classification was computed on MATLAB (Ensemble of decision trees based TreeBagger function). Briefly, 4 -wk $\mathrm{Bad}^{+/+}$and 5 -wk Bad ${ }^{+/+}$protein profiles were used as training data (using 5000 decision trees) and all samples were subsequently scored (probability of being classified as 4-weeks or 5-weeks $\mathrm{Bad}^{+/+}$ protein profile) based on the trained model.

Gene ontology and pathway analysis. For RPPA data, differential candidates were derived from analysis of variance $p$-values $(p<0.05)$, indicative of significantly different total/phosphoproteins levels amongst the groups. These candidates (Supplementary Data 2) were subjected to Pathway analysis scoring using the Enrichr web application ${ }^{103}$.

For mass spectrometry data, differential protein expression between experimental conditions was determined by performing pair-wise analyses of 
relative protein abundance observed between experimental conditions. Comparisons were limited to proteins observed in at least $n=3$ of 10 samples. Two-tailed heteroscedastic $T$-tests were performed on relative protein abundances between experimental conditions, with resultant $p$-values being uploaded to qvalue. princeton.edu to generate false-discovery rates. Additionally, differences in proteins' relative abundance between experimental conditions was determined by generating $\log 2$ ratios of experimental conditions' proteins' average relative abundance, with proteins uniquely observed given an arbitrary $\log 2$ value of \pm 10 . Significance for differential protein abundance between experimental conditions was determined using either $p<0.05$ and/or a $\log 2$ ratio of \pm 2 (indicating a 4 -fold change). Proteins determined to be preferentially abundant for a given experimental condition were grouped and subject to GO analysis using the Enrichr web application.

Graphing, statistics, and reproducibility. Graphing was done on GraphPad prism (Graphpad Software, La Jolla, CA, USA) and MATLAB. All error bars in bar graphs are represented as mean \pm standard deviation. For all Tukey boxplots, notch indicates $95 \%$ confidence interval around the median line, box edges are 25th and 75th percentiles, whiskers extend to extreme data points excluding "outliers" (individual "outliers" are plotted as black dots). Overlaid circle and error bars are the mean \pm standard error of mean. For WMs morphological analysis bar plots, all western blots and RPPA bar plots: two-tailed unpaired $t$-test was used for 2 groups, while ANOVA and subsequent Tukey-Kramer's post hoc test was used for multicomparison of 3 or more groups. For all other imaging data: two-sided Wilcoxon rank-sum pair-wise test was used for 2 groups, while Kruskal-Wallis test followed by Dunn's pair-wise post-hoc test was used for multi-comparison of 3 or more groups. Significant $p$-values are shown in figures. All statistical tests and subsequent exact $p$-values are shown in Supplementary Data 4.

Reporting summary. Further information on research design is available in the Nature Research Reporting Summary linked to this article.

\section{Data availability}

The mass spectrometry proteomics data have been deposited in the ProteomeXchange Consortium via the PRIDE partner repository ${ }^{104}$ under the dataset identifier PXD014347. The comparative proteomic data analysis has been included in Supplementary Data 1 (Mus musculus proteome retrieved from UniprotKB 'release2015_10' version on October 16, 2015). RPPA raw data is included in Supplementary Data 2 . All data used in this study are available upon reasonable request. Source data are provided with this paper.

Received: 22 June 2020; Accepted: 20 April 2021; Published online: 19 May 2021

\section{References}

1. Yang, E. et al. Bad, a heterodimeric partner for $\mathrm{Bcl}-\mathrm{XL}$ and $\mathrm{Bcl}-2$, displaces $\mathrm{Bax}$ and promotes cell death. Cell 80, 285-291 (1995).

2. Gilmore, A. P. et al. Activation of BAD by therapeutic inhibition of epidermal growth factor receptor and transactivation by insulin-like growth factor receptor. J. Biol. Chem. 277, 27643-27650 (2002).

3. Kitada, S. et al. Expression and location of pro-apoptotic Bcl-2 family protein $\mathrm{BAD}$ in normal human tissues and tumor cell lines. Am. J. Pathol. 152, 51-61 (1998).

4. Zha, J. et al. BH3 domain of BAD is required for heterodimerization with BCL-XL and pro-apoptotic activity. J. Biol. Chem. 272, 24101-24104 (1997).

5. Danial, N. N. BAD: undertaker by night, candyman by day. Oncogene $\mathbf{2 7}, 53$ (2008).

6. Giménez-Cassina, A. \& Danial, N. N. Regulation of mitochondrial nutrient and energy metabolism by BCL-2 family proteins. Trends Endocrinol. Metab. 26, 165-175 (2015).

7. Datta, S. R. et al. Survival factor-mediated BAD phosphorylation raises the mitochondrial threshold for apoptosis. Dev. Cell 3, 631-643 (2002).

8. Ranger, A. M. et al. Bad-deficient mice develop diffuse large B cell lymphoma. Proc. Natl Acad. Sci. USA 100, 9324-9329 (2003).

9. Danial, N. N. et al. BAD and glucokinase reside in a mitochondrial complex that integrates glycolysis and apoptosis. Nature 424, 952-956 (2003).

10. Danial, N. N. et al. Dual role of proapoptotic BAD in insulin secretion and beta cell survival. Nat. Med. 14, 144-153 (2008).

11. Foley, J., Burnham, V., Tedoldi, M., Danial, N. N. \& Yellen, G. BAD knockout provides metabolic seizure resistance in a genetic model of epilepsy with sudden unexplained death in epilepsy. Epilepsia 59, e1-e4 (2018).

12. Craik, A. C. et al. The BH3-only protein Bad confers breast cancer taxane sensitivity through a nonapoptotic mechanism. Oncogene 29, 5381-5391 (2010).
13. Mann, J. et al. Non-canonical BAD activity regulates breast cancer cell and tumor growth via 14-3-3 binding and mitochondrial metabolism. Oncogene 38, 3325-3339 (2019)

14. Mann, J. et al. BAD sensitizes breast cancer cells to docetaxel with increased mitotic arrest and necroptosis. Sci. Rep. 10, 355 (2020).

15. Schuler, F. et al. The BH3-only protein BIM contributes to late-stage involution in the mouse mammary gland. Cell Death Differ. 23, 41-51 (2016).

16. Karamboulas, C. \& Ailles, L. Developmental signaling pathways in cancer stem cells of solid tumors. Biochim. Biophys. Acta 1830, 2481-2495 (2013).

17. Rangel, M. C. et al. Developmental signaling pathways regulating mammary stem cells and contributing to the etiology of triple-negative breast cancer. Breast Cancer Res. Treat. 156, 211-226 (2016).

18. Saxena, M. \& Christofori, G. Rebuilding cancer metastasis in the mouse. Mol. Oncol. 7, 283-296 (2013).

19. Wiseman, B. S. \& Werb, Z. Stromal effects on mammary gland development and breast cancer. Science 296, 1046-1049 (2002).

20. Paine, I. S. \& Lewis, M. T. The terminal end bud: the little engine that could. J. Mammary Gland Biol. Neoplasia 22, 93-108 (2017).

21. Ewald, A. J. et al. Mammary collective cell migration involves transient loss of epithelial features and individual cell migration within the epithelium. J. Cell. Sci. 125, 2638-2654 (2012).

22. Yamada, K. M. \& Sixt, M. Mechanisms of 3D cell migration. Nat. Rev. Mol. Cell Biol. 20, 738-752 (2019).

23. Mardakheh, F. K. et al. Global analysis of mRNA, translation, and protein localization: local translation is a key regulator of cell protrusions. Dev. Cell 35, 344-357 (2015).

24. Stuart, H. C. et al. Localized Rho GTPase activation regulates RNA dynamics and compartmentalization in tumor cell protrusions. J. Biol. Chem. 283, 34785-34795 (2008)

25. Liao, G., Mingle, L., Van De Water, L. \& Liu, G. Control of cell migration through mRNA localization and local translation. Wiley Interdiscip. Rev. RNA 6, 1-15 (2015).

26. Boac, B. M. et al. Expression of the BAD pathway is a marker of triplenegative status and poor outcome. Sci. Rep. 9, 17496 (2019).

27. Hennighausen, L. \& Robinson, G. W. Signaling pathways in mammary gland development. Dev. Cell 1, 467-475 (2001).

28. Sternlicht, M. D., Kouros-Mehr, H., Lu, P. \& Werb, Z. Hormonal and local control of mammary branching morphogenesis. Differentiation 74, 365-381 (2006).

29. Sternlicht, M. D. Key stages in mammary gland development: the cues that regulate ductal branching morphogenesis. Breast Cancer Res. 8, 201 (2006).

30. Howlin, J., McBryan, J. \& Martin, F. Pubertal mammary gland development: insights from mouse models. J. Mammary Gland Biol. Neoplasia 11, 283-297 (2006).

31. Nguyen-Ngoc, K. V. \& Ewald, A. J. Mammary ductal elongation and myoepithelial migration are regulated by the composition of the extracellular matrix. J. Microsc. 251, 212-223 (2013).

32. Nguyen-Ngoc, K. V. et al. 3D culture assays of murine mammary branching morphogenesis and epithelial invasion. Methods Mol. Biol. 1189, 135-162 (2015).

33. Ewald, A. J., Brenot, A., Duong, M., Chan, B. S. \& Werb, Z. Collective epithelial migration and cell rearrangements drive mammary branching morphogenesis. Dev. Cell. 14, 570-581 (2008).

34. Andrew, D. J. \& Ewald, A. J. Morphogenesis of epithelial tubes: Insights into tube formation, elongation, and elaboration. Dev. Biol. 341, 34-55 (2010).

35. McNally, S. \& Stein, T. Overview of mammary gland development: a comparison of mouse and human. Methods Mol. Biol. 1501, 1-17 (2017).

36. Krause, S. et al. Dual regulation of breast tubulogenesis using extracellular matrix composition and stromal cells. Tissue Eng. Part A 18, 520-532 (2012)

37. Barnes, C. et al. From single cells to tissues: interactions between the matrix and human breast cells in real time. PLoS ONE 9, e93325 (2014).

38. Dhimolea, E., Maffini, M. V., Soto, A. M. \& Sonnenschein, C. The role of collagen reorganization on mammary epithelial morphogenesis in a 3D culture model. Biomaterials 31, 3622-3630 (2010).

39. Accornero, P. et al. Met receptor acts uniquely for survival and morphogenesis of EGFR-dependent normal mammary epithelial and cancer cells. PLoS ONE 7, e44982 (2012).

40. Caliński, T. \& Harabasz, J. A dendrite method for cluster analysis. Commun. Stat. 3, 1-27 (1974)

41. Choi, C. K. et al. Actin and alpha-actinin orchestrate the assembly and maturation of nascent adhesions in a myosin II motor-independent manner. Nat. Cell Biol. 10, 1039-1050 (2008).

42. Fessenden, T. B. et al. Dia1-dependent adhesions are required by epithelial tissues to initiate invasion. J. Cell Biol. 217, 1485-1502 (2018).

43. Kelekar, A., Chang, B. S., Harlan, J. E., Fesik, S. W. \& Thompson, C. B. Bad is a $\mathrm{BH} 3$ domain-containing protein that forms an inactivating dimer with BclXL. Mol. Cell Biol. 17, 7040-7046 (1997). 
44. Stingl, J. et al. Purification and unique properties of mammary epithelial stem cells. Nature 439, 993-997 (2006).

45. Prater, M., Shehata, M., Watson, C. J. \& Stingl, J. Enzymatic dissociation, flow cytometric analysis, and culture of normal mouse mammary tissue. Methods Mol. Biol. 946, 395-409 (2013).

46. Prater, M. D. et al. Mammary stem cells have myoepithelial cell properties. Nat. Cell Biol. 16, 942-947 (2014).

47. Li, J. et al. Characterization of human cancer cell lines by reverse-phase protein arrays. Cancer Cell. 31, 225-239 (2017).

48. Akbani, R. et al. A pan-cancer proteomic perspective on The Cancer Genome Atlas. Nat. Commun. 5, 3887 (2014).

49. Akbani, R. et al. Realizing the promise of reverse phase protein arrays for clinical, translational, and basic research: a workshop report: the RPPA (reverse phase protein array) society. Mol. Cell Proteom. 13, 1625-1643 (2014).

50. Gingras, A. C. et al. Regulation of 4E-BP1 phosphorylation: a novel two-step mechanism. Genes Dev. 13, 1422-1437 (1999).

51. Gingras, A. C. et al. Hierarchical phosphorylation of the translation inhibitor 4E-BP1. Genes Dev. 15, 2852-2864 (2001).

52. Yanagiya, A. et al. Translational homeostasis via the mRNA cap-binding protein, eIF4E. Mol. Cell 46, 847-858 (2012).

53. Whyte, J., Bergin, O., Bianchi, A., McNally, S. \& Martin, F. Key signalling nodes in mammary gland development and cancer. Mitogen-activated protein kinase signalling in experimental models of breast cancer progression and in mammary gland development. Breast Cancer Res. 11, 209 (2009).

54. Wickenden, J. A. \& Watson, C. J. Key signalling nodes in mammary gland development and cancer. Signalling downstream of PI3 kinase in mammary epithelium: a play in 3 Akts. Breast Cancer Res. 12, 202 (2010).

55. Ridley, A. J. Life at the leading edge. Cell 145, 1012-1022 (2011).

56. Kim, N. Y. et al. Optogenetic control of mRNA localization and translation in live cells. Nat. Cell Biol. 22, 341-352 (2020).

57. Schmidt, E. K., Clavarino, G., Ceppi, M. \& Pierre, P. SUnSET, a nonradioactive method to monitor protein synthesis. Nat. Methods 6, 275-277 (2009).

58. Nathans, D. Puromycin inhibition of protein synthesis: incorporation of puromycin into peptide chains. Proc. Natl Acad. Sci. USA 51, 585-592 (1964).

59. Metcalfe, A. D. et al. Developmental regulation of Bcl-2 family protein expression in the involuting mammary gland. J. Cell. Sci. 112(Pt 11), 1771-1783 (1999).

60. Hinck, L. \& Silberstein, G. B. Key stages in mammary gland development: the mammary end bud as a motile organ. Breast Cancer Res. 7, 245-251 (2005).

61. Friedl, P. \& Wolf, K. Plasticity of cell migration: a multiscale tuning model. J. Cell Biol. 188, 11-19 (2010).

62. Morrison, M. M. et al. mTOR Directs breast morphogenesis through the PKCalpha-Racl signaling axis. PLoS Genet. 11, e1005291 (2015).

63. Pond, A. C. et al. Fibroblast growth factor receptor signaling is essential for normal mammary gland development and stem cell function. Stem Cells 31, 178-189 (2013).

64. Hens, J. R. \& Wysolmerski, J. J. Key stages of mammary gland development: molecular mechanisms involved in the formation of the embryonic mammary gland. Breast Cancer Res. 7, 220-224 (2005).

65. Peuhu, E. et al. SHARPIN regulates collagen architecture and ductal outgrowth in the developing mouse mammary gland. EMBO J. 36, 165-182 (2017).

66. Qin, X., Jiang, B. \& Zhang, Y. 4E-BP1, a multifactor regulated multifunctional protein. Cell Cycle 15, 781-786 (2016).

67. Ma, X. M. \& Blenis, J. Molecular mechanisms of mTOR-mediated translational control. Nat. Rev. Mol. Cell Biol. 10, 307-318 (2009).

68. Villalonga, P., Fernández de Mattos, S. \& Ridley, A. J. RhoE inhibits 4E-BP1 phosphorylation and eIF4E function impairing cap-dependent translation. J. Biol. Chem. 284, 35287-35296 (2009).

69. Mitchell, D. C., Menon, A. \& Garner, A. L. Chemoproteomic profiling uncovers CDK4-mediated phosphorylation of the translational suppressor 4EBP1. Cell Chem. Biol. 26, 980-990.e8 (2019).

70. Shuda, M. et al. CDK1 substitutes for mTOR kinase to activate mitotic capdependent protein translation. Proc. Natl Acad. Sci. USA 112, 5875-5882 (2015).

71. Zhang, Y. \& Zheng, X. F. S. mTOR-independent 4E-BP1 phosphorylation is associated with cancer resistance to mTOR kinase inhibitors. Cell Cycle 11, 594-603 (2012).

72. Ducker, G. S. et al. Incomplete inhibition of phosphorylation of 4E-BP1 as a mechanism of primary resistance to ATP-competitive mTOR inhibitors. Oncogene 33, 1590-1600 (2014).

73. Choo, A. Y., Yoon, S., Kim, S. G., Roux, P. P. \& Blenis, J. Rapamycin differentially inhibits S6Ks and 4E-BP1 to mediate cell-type-specific repression of mRNA translation. Proc. Natl Acad. Sci. USA 105, 17414-17419 (2008).
74. Roy, S. S. et al. Bad targets the permeability transition pore independent of Bax or Bak to switch between Ca2+-dependent cell survival and death. Mol. Cell 33, 377-388 (2009).

75. Mazor, K. M. et al. Effects of single amino acid deficiency on mRNA translation are markedly different for methionine versus leucine. Sci. Rep. 8, 8076 (2018).

76. Huebner, R. J., Neumann, N. M. \& Ewald, A. J. Mammary epithelial tubes elongate through MAPK-dependent coordination of cell migration. Development 143, 983-993 (2016).

77. Liao, G., Mingle, L., Van De Water, L. \& Liu, G. Control of cell migration through mRNA localization and local translation. Wiley Interdiscip. Rev. RNA 6, 1-15 (2015).

78. Jung, H., Gkogkas, C. G., Sonenberg, N. \& Holt, C. E. Remote control of gene function by local translation. Cell 157, 26-40 (2014).

79. Hüttelmaier, S. et al. Spatial regulation of beta-actin translation by Srcdependent phosphorylation of ZBP1. Nature 438, 512-515 (2005).

80. Willett, M., Brocard, M., Davide, A. \& Morley, S. J. Translation initiation factors and active sites of protein synthesis co-localize at the leading edge of migrating fibroblasts. Biochem. J. 438, 217-227 (2011).

81. Willett, M., Pollard, H. J., Vlasak, M. \& Morley, S. J. Localization of ribosomes and translation initiation factors to talin/beta3-integrin-enriched adhesion complexes in spreading and migrating mammalian cells. Biol. Cell 102, 265-276 (2010).

82. Neumann, N. M. et al. Coordination of receptor tyrosine kinase signaling and interfacial tension dynamics drives radial intercalation and tube elongation. Dev. Cell 45, 67-82.e6 (2018).

83. Katz, Z. B. et al. Mapping translation 'hot-spots' in live cells by tracking single molecules of mRNA and ribosomes. Elife 5, https://doi.org/10.7554/eLife.10415 (2016).

84. Rousseau, D., Kaspar, R., Rosenwald, I., Gehrke, L. \& Sonenberg, N. Translation initiation of ornithine decarboxylase and nucleocytoplasmic transport of cyclin D1 mRNA are increased in cells overexpressing eukaryotic initiation factor 4E. Proc. Natl Acad. Sci. USA 93, 1065-1070 (1996).

85. Morita, M. et al. mTORC1 controls mitochondrial activity and biogenesis through 4E-BP-dependent translational regulation. Cell Metab. 18, 698-711 (2013).

86. Willimott, S., Beck, D., Ahearne, M. J., Adams, V. C. \& Wagner, S. D. Captranslation inhibitor, 4EGI-1, restores sensitivity to ABT-737 apoptosis through cap-dependent and -independent mechanisms in chronic lymphocytic leukemia. Clin. Cancer Res. 19, 3212-3223 (2013).

87. Tcherkezian, J. et al. Proteomic analysis of cap-dependent translation identifies LARP1 as a key regulator of 5'TOP mRNA translation. Genes Dev. 28, 357-371 (2014).

88. Dowling, R. J. O. et al. mTORC1-mediated cell proliferation, but not cell growth, controlled by the 4E-BPs. Science 328, 1172-1176 (2010).

89. Eliseeva, I., Vasilieva, M. \& Ovchinnikov, L. P. Translation of human $\beta$-actin mRNA is regulated by mTOR pathway. Genes (Basel) 10, 96 (2019).

90. Andreev, D. E. et al. Differential contribution of the m7G-cap to the 5' enddependent translation initiation of mammalian mRNAs. Nucleic Acids Res. 37, 6135-6147 (2009)

91. Andrews, M. G., Subramanian, L. \& Kriegstein, A. R. mTOR signaling regulates the morphology and migration of outer radial glia in developing human cortex. Elife 9, https://doi.org/10.7554/eLife.58737 (2020).

92. Leung, K. et al. Asymmetrical beta-actin mRNA translation in growth cones mediates attractive turning to netrin-1. Nat. Neurosci. 9, 1247-1256 (2006).

93. Katz, Z. B. et al. beta-Actin mRNA compartmentalization enhances focal adhesion stability and directs cell migration. Genes Dev. 26, 1885-1890 (2012).

94. Plante, I., Stewart, M. K. G. \& Laird, D. W. Evaluation of mammary gland development and function in mouse models. J.Vis. Exp. 2828 (2011).

95. Dunphy, K. A., Tao, L. \& Jerry, D. J. Mammary epithelial transplant procedure. J. Vis. Exp. 1849 (2010).

96. Gao, H. et al. Murine mammary stem/progenitor cell isolation: different method matters? Springerplus 5, 140-143 (2016).

97. Debnath, J., Muthuswamy, S. K. \& Brugge, J. S. Morphogenesis and oncogenesis of MCF-10A mammary epithelial acini grown in threedimensional basement membrane cultures. Methods 30, 256-268 (2003).

98. Nie, M. \& Htun, H. Different modes and potencies of translational repression by sequence-specific RNA-protein interaction at the 5'-UTR. Nucleic Acids Res. 34, 5528-5540 (2006).

99. Sarbassov, D. D., Guertin, D. A., Ali, S. M. \& Sabatini, D. M. Phosphorylation and regulation of Akt/PKB by the rictor-mTOR complex. Science 307, 1098-1101 (2005).

100. Nehdi, A. et al. Deficiency in either 4E-BP1 or 4E-BP2 augments innate antiviral immune responses. PLoS ONE 9, e114854 (2014).

101. Githaka, J. M. et al. Ligand-induced growth and compaction of CD36 nanoclusters enriched in Fyn induces Fyn signaling. J. Cell. Sci. 129, 4175-4189 (2016). 
102. Kramer, D. A., Eldeeb, M. A., Wuest, M., Mercer, J. \& Fahlman, R. P. Proteomic characterization of EL4 lymphoma-derived tumors upon chemotherapy treatment reveals potential roles for lysosomes and caspase- 6 during tumor cell death in vivo. Proteomics 17, 1700060 (2017).

103. Kuleshov, M. V. et al. Enrichr: a comprehensive gene set enrichment analysis web server 2016 update. Nucleic Acids Res. 44, 90 (2016).

104. Perez-Riverol, Y. et al. The PRIDE database and related tools and resources in 2019: improving support for quantification data. Nucleic Acids Res. 47, D442-D450 (2019).

\section{Acknowledgements}

We are grateful to all Goping lab members for their valuable discussions and contribution. We thank Dr. Tommy Alain for graciously sharing 4E-BP1 shRNA plasmid and Drs. Elena Posse de Chaves, Thomas Simmen, and Hanne Ostergaard for their generous gift of antibodies. ISG acknowledges the Lilian McCullough Chair in Breast Cancer Research. This work was supported by operating grants from the Alberta Cancer Foundation and Canadian Institutes of Health Research to ISG.

\section{Author contributions}

I.S.G. and D.A.U. conceived the study. J.M.G., N.T., and I.S.G., designed research. J.M.G., N.T., R.K., N.P., V.P., R.M., L.F.Z., and D.A.K. performed the experiments. N.D. provided mouse strains. N.D. and N.S. provided expertise. J.M.G. and D.A.K. analyzed the data. I.S.G. and R.P.F. directed research. J.M.G. and I.S.G. wrote the paper.

\section{Competing interests}

The authors declare no competing interests.

\section{Additional information}

Supplementary information The online version contains supplementary material available at https://doi.org/10.1038/s41467-021-23269-8.

Correspondence and requests for materials should be addressed to I.S.G.

Peer review information Nature Communications thanks the anonymous reviewer(s) for their contribution to the peer review of this work. Peer reviewer reports are available.

Reprints and permission information is available at http://www.nature.com/reprints

Publisher's note Springer Nature remains neutral with regard to jurisdictional claims in published maps and institutional affiliations.

(c) Open Access This article is licensed under a Creative Commons Attribution 4.0 International License, which permits use, sharing, adaptation, distribution and reproduction in any medium or format, as long as you give appropriate credit to the original author(s) and the source, provide a link to the Creative Commons license, and indicate if changes were made. The images or other third party material in this article are included in the article's Creative Commons license, unless indicated otherwise in a credit line to the material. If material is not included in the article's Creative Commons license and your intended use is not permitted by statutory regulation or exceeds the permitted use, you will need to obtain permission directly from the copyright holder. To view a copy of this license, visit http://creativecommons.org/ licenses/by/4.0/.

(c) The Author(s) 2021 